\title{
Quantifying the added value of convection-permitting climate simulations in complex terrain: a systematic evaluation of WRF over the Himalayas
}

\author{
Ramchandra Karki $^{1,2}$, Shabeh ul Hasson ${ }^{1,3}$, Lars Gerlitz ${ }^{4}$, Udo Schickhoff ${ }^{1}$, Thomas Scholten ${ }^{5}$, and \\ Jürgen Böhner $^{1}$ \\ ${ }^{1}$ Center for Earth System Research and Sustainability, Institute of Geography, University of Hamburg, \\ Bundesstraße 55, 20146 Hamburg, Germany \\ ${ }^{2}$ Department of Hydrology and Meteorology, Government of Nepal, 406 Naxal, Kathmandu, Nepal \\ ${ }^{3}$ Department of Space Sciences, Institute of Space Technology, Islamabad 44000, Pakistan \\ ${ }^{4}$ Section Hydrology, GFZ German Research Centre for Geosciences, Telegrafenberg, 14473 Potsdam, Germany \\ ${ }^{5}$ Soil Science and Geomorphology, University of Tübingen, Department of Geosciences, Rümelinstrasse \\ 19-23, 72070 Tübingen, Germany
}

Correspondence to: Ramchandra Karki (ramchandra.karki@studium.uni-hamburg.de)

Received: 27 March 2017 - Discussion started: 5 April 2017

Accepted: 31 May 2017 - Published: 5 July 2017

\begin{abstract}
Mesoscale dynamical refinements of global climate models or atmospheric reanalysis have shown their potential to resolve intricate atmospheric processes, their land surface interactions, and subsequently, realistic distribution of climatic fields in complex terrains. Given that such potential is yet to be explored within the central Himalayan region of Nepal, we investigate the skill of the Weather Research and Forecasting (WRF) model with different spatial resolutions in reproducing the spatial, seasonal, and diurnal characteristics of the near-surface air temperature and precipitation as well as the spatial shifts in the diurnal monsoonal precipitation peak over the Khumbu (Everest), Rolwaling, and adjacent southern areas. Therefore, the ERA-Interim $\left(0.75^{\circ}\right)$ reanalysis has been dynamically refined to 25,5 , and $1 \mathrm{~km}(\mathrm{D} 1, \mathrm{D} 2$, and D3) for one complete hydrological year (October 2014-September 2015), using the one-way nested WRF model run with mild nudging and parameterized convection for the outer but explicitly resolved convection for the inner domains. Our results suggest that D3 realistically reproduces the monsoonal precipitation, as compared to its underestimation by D1 but overestimation by D2. All three resolutions, however, overestimate precipitation from the westerly disturbances, owing to simulating anomalously higher intensity of few intermittent events. Temperatures are generally reproduced well by all resolutions; however, winter and pre-monsoon seasons feature a high cold bias for high elevations while lower elevations show a simultaneous warm bias. Unlike higher resolutions, D1 fails to realistically reproduce the regional-scale nocturnal monsoonal peak precipitation observed in the Himalayan foothills and its diurnal shift towards high elevations, whereas D2 resolves these characteristics but exhibits a limited skill in reproducing such a peak on the river valley scale due to the limited representation of the narrow valleys at $5 \mathrm{~km}$ resolution. Nonetheless, featuring a substantial skill over D1 and D2, D3 simulates almost realistic shapes of the seasonal and diurnal precipitation and the peak timings even on valley scales. These findings clearly suggest an added value of the convective-scale resolutions in realistically resolving the topoclimates over the central Himalayas, which in turn allows simulating their interactions with the synoptic-scale weather systems prevailing over high Asia.
\end{abstract}




\section{Background}

Featuring a complex terrain along a $2500 \mathrm{~km}$ arc, the Himalaya barrier contributes extensively to redefining the regional climate: (1) by controlling the cold and dry air advection from central Asia and (2) by enhancing and redistributing the incident precipitation (Norris et al., 2015). Hence, the Himalayas play a crucial role in defining the regions' hydrometeorology and hydrology, which in turn ensures the food and water security of 1.6 billion people and the sustainable development of the agrarian economies downstream.

Since Nepal is situated in the center of the Himalayan arc, its climate also results from a sophisticated interaction between the steep and complex Himalayan terrain and the two large-scale circulation modes: the south Asian summer monsoon and the high-level baroclinic westerlies. The hydro-climatology of Nepal is dominated by the south Asian summer monsoon that provides more than $80 \%$ of the total annual precipitation, as winter is mostly dry and cold (Shrestha, 2000; Karki et al., 2017). Being a monsoondominated mountainous region, Nepal is highly susceptible to the developments of heavy rainfall that trigger hydrometeorological disasters, threaten the food and water security and cause the loss of life. Such problems of food and water security and disaster management in Nepal and the Himalayas seems to be further exacerbated by the observed warming and its altitude-dependent intensification, the thinning and retreat of glaciers, the formation and expansion of glacial lakes, the shift of tree line to higher elevations, changes in precipitation seasonality, and the increasing frequency and severity of floods and droughts (Karki et al., 2009, 2017; Soncini et al., 2016; Schickhoff et al., 2015; Hasson et al., 2016a). Such vulnerability and exposure of the mountainous communities to the adverse socioeconomic impacts of changing climate and its induced disasters greatly highlights the importance of understanding their drivers and their subsequent impacts on various sectors of life for devising local-scale adaptation strategies. This requires, above all, fine-scale climatic information, particularly of surface air temperature (hereinafter temperature) and precipitation, which are also amongst the essential inputs to impact assessment models (Böhner and Lehmkuhl, 2005; Karmacharya et al., 2016; Gerlitz et al., 2016).

However, meteorological observations are too sparse in the region, while spatially complete gridded (interpolated or remotely sensed) observations, reanalysis products, and regional-to-global scale climate models' datasets are too coarse to represent the topoclimates over the deep and broad river valleys and over the steep slopes and ridges of the complex Himalayan terrain (Lang and Barros, 2004; Palazzi et al., 2013; Gerlitz et al., 2016; Hasson et al., 2016b). Consequently, the interaction of the distinct synoptic to mesoscale circulations with local topoclimates is yet understood only indistinctly. Thus, a better understanding of the local atmospheric processes and their interaction with prevailing circu- lation modes over the complex Himalayan terrain largely depends upon fine-scale climate model simulations featuring a satisfactory representation of the present climate (Hasson et al., 2016c), usually obtained through dynamical downscaling of reanalysis products.

The Weather Research and Forecasting (WRF) model is a proven tool to dynamically downscale at very high resolutions $(<10 \mathrm{~km})$ in a complex mountainous terrain (Rasmussen et al., 2011; Viale et al., 2013; Jiménez and Dudhia, 2013). Unlike temperature, WRF does not necessarily show an improvement for precipitation when going to high resolutions, and there are regional differences. For example, over the Tibetan plateau (TP), Maussion et al. (2014) have shown that the spatial patterns, interannual variability, and seasonality of precipitation are reproduced well by WRF simulations performed at 30 and $10 \mathrm{~km}$, with the latter one showing relative improvements. But over the central Himalayas - where topography is relatively complex as compared to $\mathrm{TP}$ - their $10 \mathrm{~km}$ simulation suggests an underestimation of monsoonal precipitation by half. By contrast, over the central Himalayas, the $6.7 \mathrm{~km}$ convection-permitting WRF simulation by Norris et al. (2016) suggests an overestimation up to twice that of observed monsoonal precipitation. Focusing on the small Langtang catchment in Nepal, Collier and Immerzeel (2015) even illustrated the poor performance of $5 \mathrm{~km}$ convection-permitting WRF simulations featuring a higher underestimation of monsoonal precipitation compared to $25 \mathrm{~km}$ resolution simulations with parameterized convection. Such regionally distinct WRF results could be due to the extremely heterogeneous terrain and varied microclimates of the Himalayas.

The diurnal distribution of precipitation is another important characteristic of the monsoonal precipitation, as it controls the circulation characteristics (latent heat release) and affects the precipitation magnitude (Sato et al., 2008; Bhatt et al., 2014; Shrestha and Desar, 2014). Hence, a better imitation of the diurnal cycle characteristics by the climate models can ensure their realistic representation of the monsoonal precipitation and particularly their topoclimatic driving factors. However, at coarser horizontal resolutions $(>15 \mathrm{~km})$, WRF has shown a deficiency in simulating even large-scale midnight to early-morning peak precipitation, evident in the Himalayan foothills (Bhate et al., 2012). Although a $12 \mathrm{~km}$ WRF run broadly reproduces the principal shape of the diurnal cycle but fails to capture the lull precipitation hour, the timing of the diurnal peak, and its southward migration (Bhatt et al., 2014). Besides horizontal resolution, convection parameterizations can also greatly affect the climate model's performance in reproducing the distributional characteristics of diurnal precipitation. Investigating four different model resolutions $(28,14,7$, and $3.5 \mathrm{~km})$ over the Tibetan Plateau for April, Sato et al. (2008) demonstrated that only high-resolution $(<7 \mathrm{~km})$ and convection-permitting (non-parameterized convection) runs reproduce a proper development of local afternoon clouds and diurnal features. 
Norris et al. (2016) also showcased a relative improvement of $6.7 \mathrm{~km}$ convection-permitting WRF simulation over the coarser and parameterized-convection simulation in reproducing the nocturnal precipitation magnitude. Concurrently, their simulation failed to resolve the nocturnal peak, evident in the mountainous river valleys, such as Khumbu. Collier and Immerzeel (2015) evaluated the WRF simulation at $1 \mathrm{~km}$ resolution over a very small area; however, they did not analyze the spatial pattern of diurnal precipitation. Thus, it is still unclear what added value a kilometer-scale convectionpermitting simulation may have in terms of reproducing the characteristics of the diurnal cycle of precipitation over a complex Nepalese Himalayan terrain.

Mostly focusing on the monsoonal precipitation, the above studies are constrained by missing either (1) a fully explicit cloud-resolving scale $(<5 \mathrm{~km})$ or $(2)$ the assessment of impacts of high resolutions and explicitly resolved convections. Additionally, none of the studies extensively evaluated the WRF simulation against a large number of observations from different altitudinal ranges of the central Himalayas. Against this background, this study performs a systematic evaluation of a 1-year WRF simulation (October 2014-September 2015) over the highly complex terrain of Khumbu (Everest) and Rolwaling Himal in terms of reproducing the spatial distribution and annual and diurnal cycles of both temperature and precipitation and, for the latter, additionally the shift in timings of the peak precipitation hour. Further, the added value of two fine-scaled (at 5 and $1 \mathrm{~km})$ convection-permitting simulations was assessed relative to coarser $25 \mathrm{~km}$ simulation with parameterized convection, based on a dense meteorological network, including the novel observations from our TREELINE project (Gerlitz et al., 2016; Schwab et al., 2016; Müller et al., 2016a).

The remainder of the paper is organized as follows: Sect. 2 describes the study area, while Sect. 3 explains the model configuration, observations, and data analysis. Section 4 reports the WRF skill against the station observations for precipitation and temperature, where seasonal error statistics and seasonal and diurnal cycle characteristics are discussed first; then, the capability of adopted WRF resolutions in reproducing the spatial distribution of surface variables, their altitudinal gradients, and the interaction of local mountainvalley wind and large-scale circulation (responsible for monsoonal diurnal precipitation characteristics) are presented. A comparison of WRF skill across the seasons and the adopted resolutions is a particular focus. Section 5 concludes with the major findings.

\section{Study area}

The target region of the study presented spans the physiogeographic regions of Middle Mountains and the high Himalayas of Nepal and features an elevation range starting from $400 \mathrm{~m}$ a.s.l. to the world's highest peak at $8848 \mathrm{~m}$ a.s.l.
(Mt Everest). The study area contains many glaciers and glacial lakes, which are the main source of perennial freshwater supply for the downstream regions. Detailed analysis is carried out for our WRF domain D3, which mainly covers the Dudh Kosi and Tama Kosi subbasins of the Kosi River basin and surroundings, located in the northeast Nepalese Himalayas (Fig. 1b). Our primary focus is on the upstream subbasin of Dudh Kosi at Khumbu and Rolwaling, which drains to the west to Tama Kosi River.

The climate of the region varies from temperate with dry winters and hot summers in the southern river valleys to polar in the high Himalayas (Karki et al., 2016). There are mainly four typical climatic seasons: winter (December to February), pre-monsoon (March to May), monsoon (June to September), and post-monsoon (October to November). Winter precipitation mainly occurs due to extra tropical cyclones, called western disturbances, bringing moisture from the Mediterranean, Arabian, or Caspian seas (Cannon et al., 2015; Böhner et al., 2015). Norris et al. (2015) also illustrated the west and southwest cross-barrier mid-tropospheric moisture flow as the dominant factor (mechanical driver) for winter snowfall in the Himalayas. Winter precipitation is mostly received in the form of snow at high altitudes, which, though limited in volume, is vital for winter crops as well as for regulating the streamflow during hot and dry pre-monsoon season (Böhner et al., 2015). Pre-monsoon season is characterized by strong solar insolation, which results in maximum temperatures. This season is dominated with strong dry northwesterly winds. However, despite an unfavorable synoptic environment, precipitation usually observed in the evening is generated primarily by localized convective instability with heating and is supported by the mountain uplift in the areas of surplus moisture (Shrestha et al., 2012), whereas the post-monsoon is the driest season over the study region. The synoptic-scale western disturbances occasionally influence both early pre-monsoon and late post-monsoon precipitation, causing snowfall at high altitudes.

Monsoonal precipitation is characterized by strong southerly and southeasterly flow from the Bay of Bengal (Böhner, 2006; Hasson et al., 2016a, c) and contributes to more than $80 \%$ of the annual precipitation (Wagnon et al., 2013; Salerno et al., 2015; Gerlitz et al., 2016; Karki et al., 2017). Within the Khumbu region, monsoon precipitation decreases along the main river valleys between elevations of 2800 and $4500 \mathrm{~m}$ a.s.l.; however, precipitation sums around peaks and ridges are about 4-5 times larger than at valley bottoms (Higuchi et al., 1982).

The peak annual precipitation is observed around $2500 \mathrm{~m}$ a.s.l. for the Kosi Basin and sharply decreases above this height (Salerno et al., 2015). On the southern slopes of Mt Everest ( $8000 \mathrm{~m}$ a.s.l.), mean daily temperatures vary between -42 and $4{ }^{\circ} \mathrm{C}$ (Gerlitz, 2014) while lower river valleys are very hot. Other common meteorological features are locally generated, daytime up-valley and nighttime down- 


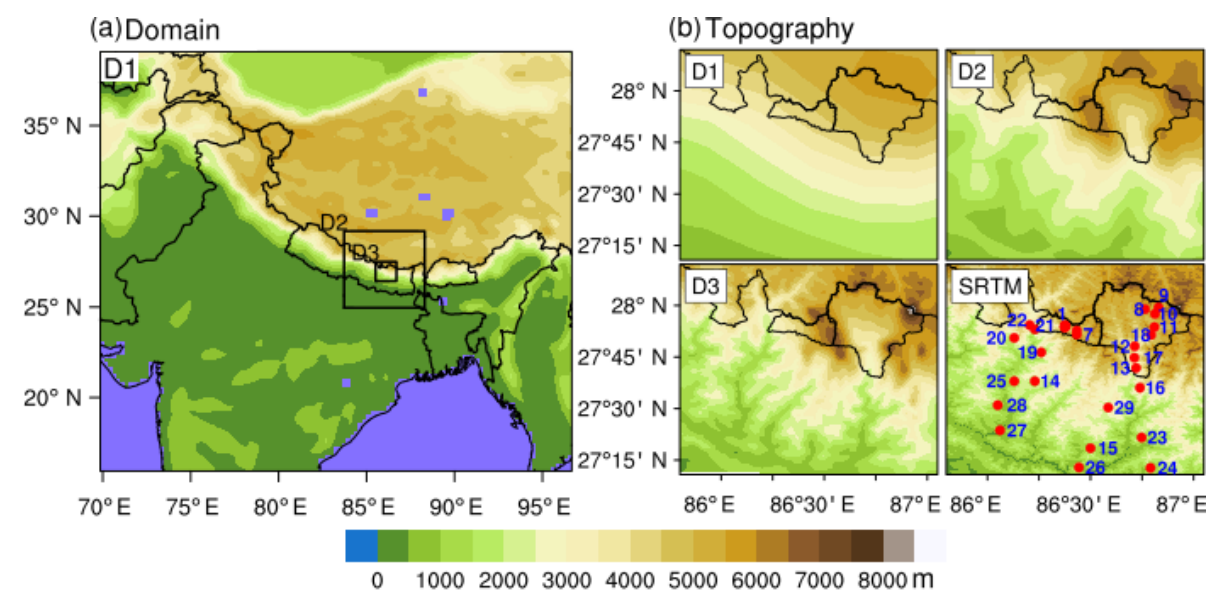

Figure 1. (a) Domain boundary of three WRF resolutions with water area marked as blue. (b) Topography of the study region at three domain resolutions - $25 \mathrm{~km}$ (D1), $5 \mathrm{~km}$ (D2), and $1 \mathrm{~km}$ (D3) - and real elevation from the Shuttle Radar Topography Mission (30 m resolution) with Rolwaling (left basin) and Khumbu catchments. Nepal political boundary is delineated in panel (b). Meteorological stations (red marker) labeled as in Table 2. Due to the dense network in Rolwaling, only stations 1 and 7 out of 1-7 are labeled.

valley winds (Ueno et al., 2008; Böhner et al., 2015; Gerlitz et al., 2016).

In general, the northward migration of the monsoonal trough (the monsoon breaks in mainland India) towards the Himalayas increases the rainfall activity and intense precipitation events over the region. When this northward-migrating monsoonal system further merges with southward-migrating upper-level extratropical westerly trough, then it often provides a highly favorable synoptic situation for bringing large amounts of moisture from both the Arabian Sea and Bay of Bengal, thereby resulting in catastrophic extreme precipitation events (Shrestha, 2016).

\section{Methods}

\subsection{Model configuration}

WRF is a fully compressible non-hydrostatic model that offers a large number of physical parameterizations and is suitable for simulating across a variety of horizontal and vertical scales. We have set up the WRF version 3.6.1 for the concurrent run of three one-way nested domains D1, D2, and D3 configured at 25,5 , and $1 \mathrm{~km}$ horizontal grid spacing, respectively (Fig. 1a). D1 spans most of the Bay of Bengal and parts of the Arabian Sea (16.0-39.9 $9^{\circ}$, 66.6-99. $\left.9^{\circ} \mathrm{E}\right)$, which are the main moisture sources of prevailing synoptic weather systems. The D2 covers more than the eastern half of Nepal along the east-west extent $\left(83.8-88.9^{\circ} \mathrm{E}\right)$ and includes the Tibetan Plateau in the north and the Indo-Gangetic plain in the south $\left(25.6-30.0^{\circ} \mathrm{N}\right)$. D3 $\left(27.2-28.3^{\circ} \mathrm{N}, 85.7-\right.$ $\left.87.1^{\circ} \mathrm{E}\right)$ covers mainly the Dudh Kosi Basin including the Khumbu Subbasin and the Tama Kosi Basin including the Rolwaling Subbasin, where stations with hourly observations are located. The setup uses $10 \operatorname{arcmin}(\sim 20 \mathrm{~km}), 2 \operatorname{arcmin}$
( $\sim 4 \mathrm{~km})$, and $30 \operatorname{arcsec}(\sim 1 \mathrm{~km})$ topography for D1, D2, and D3, respectively with USGS land cover. The real topography is thus better represented in the high-resolution domains, particularly in D3 with an offset that is mostly within $\pm 400 \mathrm{~m}$ (Figs. $1 \mathrm{~b}$ and 2). The vertical resolution of WRF was set to 50 levels (from $20 \mathrm{~m}$ height to $50 \mathrm{hPa}$ ), with the 11 lowest levels lying below the height of $1 \mathrm{~km}$ (Table 1).

The physical parameterization schemes include the Morrison microphysics scheme (most sophisticated double moment) and the planetary boundary layer scheme of MellorYamada-Nakanishi-Niino (MYNN) level 2.5. The KainFritsch (KF) cumulus parameterization option is used for D1 only. Although D2 has gray zones for explicitly resolving the convection, Collier and Immerzeel (2015) found the further worsening of precipitation output in their short-period simulation in the Himalayas with inclusion of the KF scheme (resolves shallow convection as well) compared to explicitly resolved convection on that scale. In addition, the multiyear simulation at $6 \mathrm{~km}$ with KF parameterization by one of our co-authors (Shabeh ul Hasson, personal communication, 2017) found the spuriously high precipitation in some areas for some years (not shown). For these reasons, cumulus parameterization is turned off for both D2 and D3 in order to explicitly resolve the convective precipitation processes. The setup uses the latest Noah multi-parameterization land surface model (Noah-MP LSM) (Niu et al., 2011) as it better represents the terrestrial moisture processes than the Noah LSM and relies on the shortwave and longwave radiation schemes of the NCAR community atmospheric model (Collins et al., 2004; Norris et al., 2016). The selected physics options are consistent with Collier and Immerzeel (2015), who reported an improved simulation of the surface variables over the Himalayan region. Initial and lateral boundary conditions for D1 were derived from the 
Table 1. Description of model configurations.

\begin{tabular}{lll}
\hline Description & Selection & References \\
\hline Horizontal grid spacing & $25 \mathrm{~km}(\mathrm{D} 3), 5 \mathrm{~km}(\mathrm{D} 2)$, and $1 \mathrm{~km}$ (D1) & \\
Grid dimensions & $119 \times 106,101 \times 96,131 \times 121$ & \\
Topography (land use) & 10 arcmin, 2 arcmin, and 30 arcsec (USGS) & \\
Vertical levels & $50(11$ lowest lying below 1 km) & \\
Model top pressure & $50 \mathrm{hPa}$ & \\
Nesting approach & One way & Collins et al. (2004) \\
Radiation & Community Atmosphere Model & Morrison et al. (2009) \\
Microphysics & Morrison & Kain (2004) \\
Cumulus & Kain-Fritsch (except for 5 and 1 km domains) & Nakanishi and Niino (2006) \\
Planetary boundary layer & MYNN level 2.5 & Jiménez et al. (2012) \\
Atmospheric surface layer & Monin-Obukhov (revised MM5) & Niu et al. (2011) \\
Land surface & Noah-MP & Dee et al. (2011) \\
Forcing & ERA-Interim $0.75^{\circ} \times 0.75^{\circ}, 6$ hourly & \\
\hline
\end{tabular}

ERA-Interim reanalysis, which has the spatial resolution of $0.75^{\circ} \times 0.75^{\circ}$ and the vertical resolution of 38 pressure levels (Dee et al., 2011). Both sea surface temperature (SST) and lateral boundary conditions were updated at $6 \mathrm{~h}$ interval.

Mesoscale climate models may have difficulties in representing large-scale features (Jones et al., 1995); therefore, nudging is often used for longer simulations to prevent the downscaling model from simulating completely different and unrealistic drift from the driving model and to ensure that the timings of synoptic disturbances are in phase with the driving model (Von Storch et al., 2000; Pohl and Crétat, 2014). However, the value added by nudging depends on the skill of the forcing data. Two different types of nudging termed spectral (wave numbers to filter large- and small-scale features) and grid analysis (in every grid cell) exist. Over the Himalayas, the sensitivity study of both types of the techniques by Norris et al. (2016) found no significant quantitative differences in the precipitation distribution. Thus, we have applied grid analysis nudging only to D1 and merely for the horizontal winds, potential temperature, and water vapor mixing ratio in the vertical levels above the planetary boundary layer and above the lowest 15 model levels allowing mesoscale forcing in the PBL (planetary boundary layer; lower atmosphere) as strong nudging even in the PBL, where most of the atmospheric phenomena take place, can prevent the downscaling model from representing mesoscale (smallscale features) processes (Alexandru et al., 2008). This strategy is based on previous studies which have demonstrated the improved simulation of means and extremes of surface variables with the application of such mild nudging (Otte et al., 2012; Collier and Immerzeel, 2015).

The WRF run was performed for 1 complete hydrological year with two initializations in order to optimize the available computational resources. The first initialization was performed at 00:00 UTC on 15 September 2014 (ending at 00:00 UTC on 1 June 2015), while the second initialization was performed at 00:00 UTC on 15 April 2015 (ending at 00:00 UTC on 1 October 2015). The first 15 days from the first run with wet-period initialization (Collier and Immerzeel, 2015) and first 45 days from the second run with dry-period initialization (Norris et al., 2016) were regarded as the model spin-up time to ensure the equilibrium between the boundary conditions and the model dynamics (Argüeso et al., 2012) that yielded the 1-year simulation from 1 October 2014 to 30 September 2015 .

An additional simulation was also performed from 00:00 UTC on 15 April 2015 to 00:00 UTC on 1 October 2015 for D2 (D2_st hereinafter), using a coarse 10 arcmin topography instead of the original 2 arcmin topography and keeping all other options the same as in the main simulation to test the impact of topography for resolving monsoonal precipitation and its diurnal cycle.

\subsection{Observations}

In view of the complex Nepalese Himalayan terrain, where the surface variables vary extensively within a short time and space, robust high-resolution observations are necessary for the detailed evaluation of the fine-scaled simulation (Hasson et al., 2016c). This is why the focus of D3 was set to the area hosting a relatively dense network of 29 meteorological stations, which are being maintained by four different organizations (Fig. 1b, Table 2). Within the Rolwaling, seven stations collecting $15 \mathrm{~min}$ temperature and precipitation observations are being operated by the Institute of Geography, University of Hamburg, Hamburg, as part of the TREELINE project that aims to understand the response of undisturbed tree line ecotone to the global warming (Bürzle et al., 2017). In the Khumbu region, 1 min observations from five Ev-K2CNR stations (www.evk2cnr.org) and 15 min observations from the Lukla station of the Department of Hydrology and Meteorology (DHM) are available. Further, in Khumbu valley and its surroundings, three stations from the Laboratoire Hydrosciences, CNRS, Institute of research for development 
Table 2. Summary of meteorological stations. (TP: tipping bucket; WG: weighing gauge; M: manual; D: disdrometer; $T$ : temperature; $P$ : precipitation; UH: University of Hamburg; DHM: Department of Hydrology and Meteorology; CNRS, IRD: Université de Montpellier).

\begin{tabular}{|c|c|c|c|c|c|c|c|c|c|c|}
\hline \multirow[t]{2}{*}{ No. } & \multirow[t]{2}{*}{ Station name } & \multirow[t]{2}{*}{$\begin{array}{l}\text { Latitude } \\
\text { (degree) }\end{array}$} & \multirow[t]{2}{*}{$\begin{array}{r}\text { Longitude } \\
\text { (degree) }\end{array}$} & \multirow[t]{2}{*}{$\begin{array}{r}\text { Elevation } \\
\text { (ma.s.1.) }\end{array}$} & \multirow[t]{2}{*}{ Resolution } & \multirow[t]{2}{*}{ Parameters } & \multirow[t]{2}{*}{$\begin{array}{l}\text { Precipitation } \\
\text { gauge }\end{array}$} & \multicolumn{2}{|c|}{$\begin{array}{c}\text { Data } \\
\text { availability } \\
(\%)\end{array}$} & \multirow[t]{2}{*}{ Agency } \\
\hline & & & & & & & & $T$ & $P$ & \\
\hline 1 & Gompa & 27.905 & 86.375 & 3908 & Hourly & $T, P$ & $\mathrm{TP}$ & 52 & 52 & \\
\hline 2 & T1oben & 27.897 & 86.374 & 4055 & Hourly & $T, P$ & $\mathrm{TP}$ & 100 & 100 & \\
\hline 3 & T1unten & 27.901 & 86.376 & 3739 & Hourly & $T, P$ & $\mathrm{TP}$ & 99 & 100 & \\
\hline 4 & T2unten & 27.899 & 86.379 & 3750 & Hourly & $T, P$ & $\mathrm{TP}$ & 99 & 100 & $\mathrm{UH}$ \\
\hline 5 & T2oben & 27.893 & 86.376 & 4170 & Hourly & $T, P$ & $\mathrm{TP}$ & 100 & 100 & \\
\hline 6 & $\mathrm{Na}$ & 27.878 & 86.434 & 4219 & Hourly & $T, P$ & $\mathrm{TP}$ & 100 & 100 & \\
\hline 7 & Yalun & 27.859 & 86.434 & 5032 & Hourly & $T, P$ & $\mathrm{TP}$ & 28 & 100 & \\
\hline 8 & Chungrinup & 27.982 & 86.765 & 5700 & Hourly & $T$ & & 86 & & \\
\hline 9 & Kalapathar & 27.990 & 86.830 & 5600 & Hourly & $T, P$ & $\mathrm{TP}$ & 76 & 74 & \\
\hline 10 & Pyramid & 27.959 & 86.813 & 5050 & Hourly & $T, P$ & $\mathrm{TP}$ & 50 & 55 & EVK2CNR \\
\hline 11 & Phiriche & 27.895 & 86.819 & 4260 & Hourly & $T, P$ & TP & 73 & 71 & \\
\hline 12 & Namche & 27.802 & 86.714 & 3570 & Hourly & $T, P$ & $\mathrm{TP}$ & 56 & 56 & \\
\hline 13 & Lukla & 27.697 & 86.721 & 2660 & Hourly & $T, P$ & WG & 88 & 63 & \\
\hline 14 & Jiri & 27.633 & 86.233 & 2003 & Daily & $P$ & $\mathrm{M}$ & & 92 & DHM \\
\hline 15 & Okhaldhunga & 27.308 & 86.504 & 1725 & Hourly & $T, P$ & $\mathrm{D}, \mathrm{M}$ & 100 & 99 & \\
\hline 16 & Bhalukhop & 27.601 & 86.740 & 2575 & Daily & $T, P$ & TP & 77 & 86 & \\
\hline 17 & Phakding & 27.747 & 86.713 & 2619 & Daily & $T, P$ & $\mathrm{TP}$ & 50 & 100 & CNRS, IRD \\
\hline 18 & Pangboche & 27.857 & 86.794 & 3950 & Daily & $T, P$ & $\mathrm{TP}$ & 100 & 100 & \\
\hline 19 & Chankhu & 27.773 & 86.262 & 1397 & Hourly & $P$ & $\mathrm{TP}$ & & 37 & \\
\hline 20 & Gongar & 27.843 & 86.216 & 1343 & Hourly & $P$ & $\mathrm{TP}$ & & 31 & \\
\hline 21 & Lamabagar & 27.905 & 86.205 & 1987 & Hourly & $P$ & $\mathrm{TP}$ & & 50 & \\
\hline 22 & Rikhu & 27.884 & 86.234 & 2088 & Hourly & $P$ & $\mathrm{TP}$ & & 33 & \\
\hline 23 & Aiselukharka & 27.360 & 86.749 & 2063 & Daily & $P$ & $\mathrm{M}$ & & 100 & \\
\hline 24 & Diktel & 27.213 & 86.792 & 1613 & Daily & $P$ & M & & 75 & DHM \\
\hline 25 & Kabre & 27.633 & 86.133 & 1755 & Daily & $P$ & M & & 100 & \\
\hline 26 & Mane Bhanjyang & 27.215 & 86.444 & 1528 & Daily & $P$ & M & & 67 & \\
\hline 27 & Manthali & 27.395 & 86.061 & 499 & Daily & $P$ & M & & 100 & \\
\hline 28 & Melung & 27.517 & 86.050 & 1536 & Daily & $P$ & M & & 92 & \\
\hline 29 & Salleri & 27.505 & 86.586 & 2384 & Daily & $P$ & M & & 92 & \\
\hline
\end{tabular}

(IRD), Université de Montpellier, France, provide daily observations of temperature and precipitation. In the southern hills, the DHM station of Okhaldhunga provides $15 \mathrm{~min} \mathrm{ob-}$ servations of both temperature and precipitation, while at the lower altitudes, eight DHM stations provide daily observations of precipitation only. Similarly in the lower reaches of the Rolwaling, four DHM stations provide 15 min precipitation. We have obtained all the available hourly and daily temperature and precipitation from the stations of the study area (Table 2).

It is worth noting that the type of precipitation gauge in available observational networks varies; gauges used include a manual US standard gauge, a tipping bucket, and a weighing gauge. Most of the automatic weather stations use tipping buckets without rim heating, while the manual stations use the manual US standard gauges. Relative to manual gauges, tipping buckets are known for their underestimation of rainfall by $10 \%$ (Talchabhadel et al., 2017) and for an even higher underestimation of snowfall. These gauges yield incorrect timings of the precipitation events as the solid precipitation during the night or at subzero temperature may be deposited in the upper funnel (Karki, 2012) and only contribute to the measurements after snow melting due to strong solar insolation (Shrestha et al., 2011). Further, the snowfall measurements are affected by rim snow capping, snow deposition in the upper funnel, and overflow in the case of heavy precipitation events. Goodison et al. (1998) have also pointed out that commonly used precipitation gauges strongly underestimate solid precipitation. In view of these limitations, the visual inspection of the datasets and consistency check between nearby stations within the network was performed. The values crossing general extreme limits (e.g. negative and $>500 \mathrm{~mm} \mathrm{day}^{-1}$ for precipitation and $<-40$ and $>50^{\circ} \mathrm{C}$ for temperature) and plausible station limits, constant values of temperature for the whole day, no precipitation for the whole monsoon season, and abrupt precipitation $\left(>30 \mathrm{~mm} \mathrm{~h}^{-1}\right)$ at 


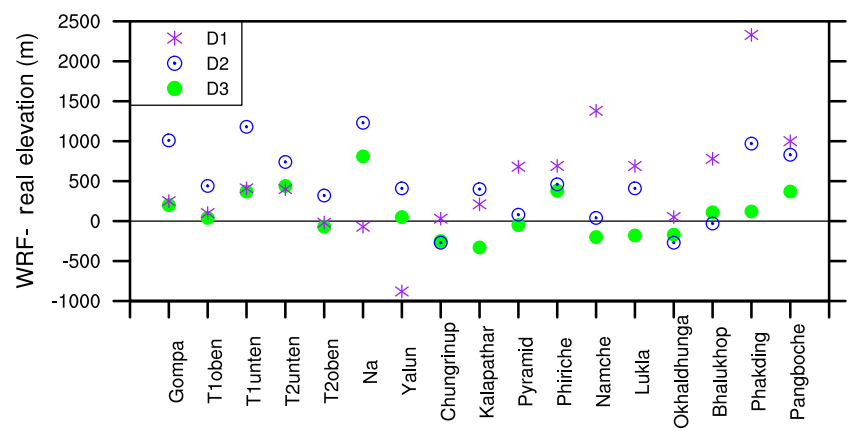

Figure 2. Difference between WRF-simulated and real elevation for three WRF resolutions at air temperature station locations.

one station but no precipitation at nearby stations (around $5 \mathrm{~km}$ ) were considered to be erroneous and excluded from analysis.

\subsection{Model validation and data analysis}

We evaluate the WRF simulations considering the abovementioned station point observations and compare them with the collocating grid point of the particular domain. The differences between the real station elevation and the associated grid cell of the WRF model, arising from the smoothed terrain of the WRF domains (Fig. 2), might lead to a systematic bias of the modeling results. Thus, simulated temperatures extracted for station locations (not for entire grids used in spatial mapping) are only adjusted using a constant lapse rate of $6^{\circ} \mathrm{C} \mathrm{km}^{-1}$, which has been observed over the whole Kosi Basin (Salerno et al., 2015). Since precipitation is highly variable in space and time, it has not been corrected. The periods of observed data gaps were ignored for the analysis.

For daily to monthly temperature validation, statistical measures of bias (WRF - observation), mean absolute error (MAE), root mean square error (RMSE), the ratio of RMSE to the standard deviation of observations (RAR), and correlation $(r)$ are applied to the all-stations pooled data (not the all-stations average). This pooling procedure, considering all station data points, is expected to better account for the localscale features in statistical analysis than averaging, which smoothes out the overall series (Soares et al., 2012). Similar measures were applied to precipitation; however, instead of bias and MAE, the normalized percentage bias (NBias) and the mean absolute percentage error (MAPE) were calculated using Eq. 1 and 2, which better handle the large number of data points with zero precipitation (Mynsbrugge, 2010).

$\begin{aligned} \text { NBias } & =\frac{100}{n} \sum_{m=1}^{n} \frac{\left(P_{m}-O\right)}{O}, \\ \text { MAPE } & =\frac{100}{n} \sum_{m=1}^{n} \frac{\left|\left(P_{m}-O\right)\right|}{O},\end{aligned}$ where $P_{m}$ refers to the WRF-simulated precipitation, $O$ refers to the mean observed precipitation, and $n$ indicates the total number of data points. For the seasonal scale, the standard normalized precipitation bias - defined as the ratio of bias to observation - is also calculated. Further, the WRF skill in simulating high-intensity precipitation and extreme temperatures is analyzed for each season by means of a percentile value comparison, given the fact that these events have huge socioeconomic and environmental consequences for the study region.

The spatially complete WRF simulations with different spatial resolution are analyzed in order to derive altitudinal gradients of surface variables. This enables the assessment of seasonal lapse rates of temperature and elevational profiles of precipitation, which are frequently required for climate impact investigations.

As the diurnal precipitation variability controls the surface energy budget (latent heat release) and water balance (Sato et al., 2008; Bhatt et al., 2014), we also analyze the diurnal precipitation characteristics. However, in view of the deficiency of tipping bucket gauges which frequently observe an artificial precipitation peak in the morning instead of during the night, we restrict our analysis to the monsoon season and to stations below elevations of $5000 \mathrm{~m}$ a.s.l. In order to investigate the topoclimatic processes, leading to a spatial differentiation of precipitation, we grouped the observations into three discrete classes. All stations located near the valley bottom are grouped into upper- and lower-valley stations based on an elevation threshold of $2500 \mathrm{~m}$ a.s.l. The stations that are located along the ridges are classified as ridge stations. We assess the WRF skill in reproducing the observed peak precipitation timing over the lower and upper valleys as well as over the mountain ridge. Besides the peak precipitation timing, we further analyze its propagation characteristics from high mountains towards the river valleys and the southern foothills (for D2 and D1) from afternoon/late-evening to midnight/early morning. In conclusion, the mountain-valley circulation and its representation in the WRF model is investigated and its interplay with spatial and diurnal precipitation characteristics is illustrated in detail.

\section{Results and discussions}

\subsection{Model validation results}

The model satisfactorily reproduces the seasonal contrasts of various dynamic and thermodynamic variables in the study region (Fig. S1 in the Supplement).

The comparison of the near-surface meteorological variables (precipitation and temperature) of the WRF simulations with the station observation in the target region revealed the following results. 


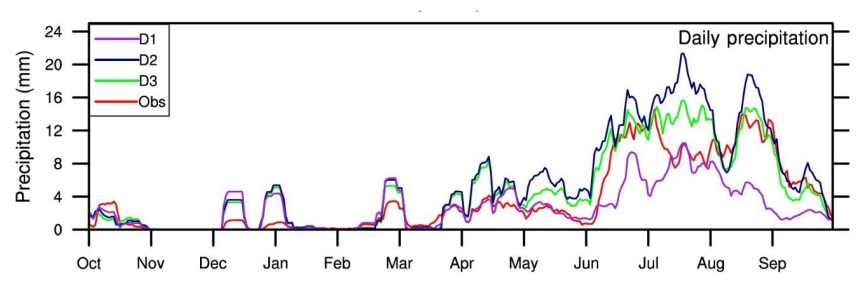

Figure 3. Daily station averaged precipitation $\left(\mathrm{mm} \mathrm{day}^{-1}\right)$ from three WRF resolutions and observation (plotted as 10-day moving average). Observation abbreviated as "obs" hereinafter in all the figures.

\subsubsection{Precipitation}

Observations show that the complex terrain of the region yields to a highly heterogeneous precipitation distribution (from 400 to $2700 \mathrm{~mm}$ annum $^{-1}$ ). In general, river valleys are found to be drier than the surrounding mountain ranges; however, a majority of precipitation falls below elevations of approximately $3500 \mathrm{~m}$ a.s.1. (exponential decrease in saturation vapor pressure with altitude). Hence, high-altitude areas and leeward slopes of high mountain ranges receive little precipitation (e.g. upstream stations of Khumbu and Rolwaling, which are described in detail in Sect. 4.2). During winter and the post-monsoon season only a few precipitation events are observed; these contribute to $\sim 6 \%$ of the annual precipitation sum. From late pre-monsoon to late-monsoon season, precipitation is permanently high and contributes to $\sim 16$ and $\sim 78 \%$ of the annual precipitation, respectively, indicating the dominance of monsoonal precipitation and moonsooninduced disasters (Fig. 3).

The seasonal error statistics of simulated daily and monthly precipitation (calculated against station observations) suggest distinct skills of each model domain, though they vary across seasons (Table 3). For monsoon, D1 features a roughly $50 \%$ negative bias, whereas D2 overestimates precipitation by up to $40 \%$. D3 also overestimates the monsoonal precipitation sum, but such a bias is below $15 \%$. Further, the relatively higher skill of D3 for the monsoon season is also evident from the majority of error statistics either calculated on daily or monthly precipitation. Winter precipitation is highly overestimated (more than a $150 \%$ bias) at all resolutions; however, the overestimation is relatively lower during the pre-monsoon and might be partially explained by the under-observation of solid precipitation by the tipping bucket gauges. Moreover, simulated precipitation variability clearly shows the ability of all WRF domains in broadly capturing the annual cycle of precipitation, featuring the highest precipitation during the monsoon months, which is followed by an abrupt decrease in the post-monsoon season (Fig. 3). D3 again shows a relatively higher skill in reproducing the annual cycle characteristics. However, precipitation is consistently overestimated by both high resolutions during the whole 2-week period in mid-monsoon (July-August); like- wise, the dry bias in D1 is significantly reduced, with its pattern closer to observation as compared to other monsoon days. A similar overestimation in WRF simulations identified by Raju et al. (2015) is attributed to excessive moisture transported from the Bay of Bengal and the western Pacific towards monsoon-dominated regions due to the strong low-level easterly wind bias. Hence, we speculate the similar mechanisms to be responsible for this consistent wet bias in our simulation too.

For daily high-intensity precipitation, all domains overestimate winter and pre-monsoon (except D1) but underestimate post-monsoon high-intensity precipitation (Fig. 4). For the dominant monsoon season, D1 underestimates, D2 overestimates, but D3 satisfactorily reproduces daily highintensity precipitation events.

As noted from the observed characteristics of the diurnal cycle presented in Fig. 5, all stations feature a lull in morning precipitation. For the upper-valley stations, distinct primary peaks are observed at midnight, while secondary peaks are observed in the late afternoon to evening (14:00-19:00 local time (LT), which is UTC + 05:45). In contrast, D2 and D3 feature a primary evening peak (16:00 LT) but a secondary peak at midnight and overestimate the precipitation intensity from the afternoon to late evening. The coarser D1 and D2_st with coarser topography only reproduces the secondary afternoon peak and highly underestimates the nighttime magnitude. D2 and D3 also slightly underestimate the nocturnal precipitation intensity from 22:00 to 03:00 LT and start precipitating 2-3 h earlier than observed. Contrary to uppervalley stations, the ridge stations show a primary precipitation peak in the evening and a secondary peak at midnight. D1 only reproduces the daytime peak but starts precipitating 2-3 h earlier. Although D2_st reproduces the daytime peak, it misses the lull in precipitation hours and starts precipitating earlier. D2 and D3 reproduce the primary evening peak timings, albeit overestimating precipitation intensity from noon (12:00 LT) to late evening (20:00 LT), but the magnitude between midnight and early morning is reproduced well.

In contrast to upper-valley and ridge stations that feature primary and secondary peaks, lower-valley stations only feature peaks in the midnight phase (Fig. 5). Further, lowervalley stations feature a linear precipitation increase from noon to midnight and a decrease from midnight to morning (09:00 LT). D1 completely fails to capture the peak precipitation timings. D2_st likewise also fails with its overestimated peak at 15:00 LT but improves the magnitude of nocturnal precipitation compared to D1, while D2, which shows an improvement over D1 and D2_st, simulates the observed midnight peak shifted to the evening ( $5 \mathrm{~h}$ early). D3 reproduces the midnight peak precipitation and its linear increase and decrease well and as observed, though slightly underestimating the precipitation intensity.

Overall, lower-valley stations are characterized by a strong nocturnal precipitation maximum during the monsoon season. The D1 simulation completely misses such a pattern, 
Table 3. Seasonal precipitation error statistics (pooled data) based on monthly and daily precipitation. (D1, D2, and D3 stands for three different domains; NBIAS: normalized bias \%; MAPE: mean absolute percentage error; $r$ : correlation; RMSE: root mean squared error; RAR: RMSE / standard deviation of observed data).

\begin{tabular}{|c|c|c|c|c|c|c|c|c|c|}
\hline \multirow[t]{2}{*}{ Error statistics } & \multicolumn{4}{|c|}{ Based on monthly precipitation } & \multirow[b]{2}{*}{ Unit } & \multicolumn{4}{|c|}{ Based on daily precipitation } \\
\hline & Winter & Pre-monsoon & Monsoon & Post-monsoon & & Winter & Pre-monsoon & Monsoon & Post-monsoon \\
\hline NBIAS_D3 & 144.4 & 77.8 & 13.8 & 5.5 & $\%$ & 150 & 78.1 & 14.5 & 15.5 \\
\hline NBIAS_D2 & 165.0 & 109.6 & 36.9 & -0.4 & $\%$ & 172 & 107.1 & 35.9 & 8.0 \\
\hline NBIAS_D1 & 189.5 & 18.9 & -44.5 & 10.0 & $\%$ & 184 & 17.1 & -42.6 & 9.4 \\
\hline MAPE_D3 & 176.4 & 104.6 & 63.4 & 118.6 & $\%$ & 322 & 205.5 & 111.0 & 182.0 \\
\hline MAPE_D2 & 197.8 & 132.8 & 81.5 & 113.7 & $\%$ & 340 & 234.3 & 131.6 & 171.7 \\
\hline MAPE_D1 & 198.4 & 72.6 & 58.7 & 119.5 & $\%$ & 350 & 145.0 & 83.6 & 157.3 \\
\hline RMSE_D3 & 32.2 & 81.9 & 146.0 & 22.1 & $\mathrm{~mm}$ & 4 & 8.7 & 16.6 & 3.9 \\
\hline RMSE_D2 & 36.0 & 106.2 & 191.8 & 23.6 & $\mathrm{~mm}$ & 4 & 10.4 & 19.5 & 4.1 \\
\hline RMSE_D1 & 33.3 & 64.0 & 212.7 & 24.5 & $\mathrm{~mm}$ & 5 & 6.6 & 13.9 & 3.4 \\
\hline RAR_D3 & 3.9 & 2.2 & 0.8 & 0.8 & & 2 & 1.7 & 1.3 & 1.1 \\
\hline RAR_D2 & 4.3 & 2.8 & 1.1 & 0.9 & & 2 & 2.0 & 1.5 & 1.2 \\
\hline RAR_D1 & 4.0 & 1.7 & 1.2 & 0.9 & & 3 & 1.3 & 1.1 & 1.0 \\
\hline$r \_\mathrm{D} 3$ & -0.07 & 0.46 & 0.70 & 0.70 & & 0.32 & 0.33 & 0.29 & 0.25 \\
\hline$r \_\mathrm{D} 2$ & -0.01 & 0.40 & 0.80 & 0.60 & & 0.31 & 0.28 & 0.25 & 0.18 \\
\hline$r \_\mathrm{D} 1$ & 0.00 & 0.22 & 0.40 & 0.60 & & 0.32 & 0.27 & 0.25 & 0.42 \\
\hline
\end{tabular}

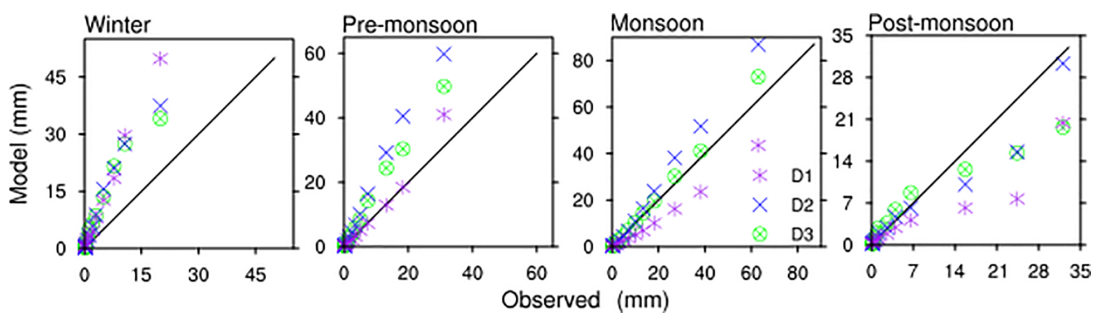

Figure 4. Percentile values comparison (for 1, 5, 10, 20, 30, 40, 50, 60, 70, 80, 90, 95, and 99) for daily precipitation at three WRF resolutions with observation for four seasons. (Percentiles calculated for precipitation $>=0.2 \mathrm{~mm} \mathrm{day}^{-1}$; therefore, this has resulted in a relatively higher value in other seasons too despite lower total precipitation).
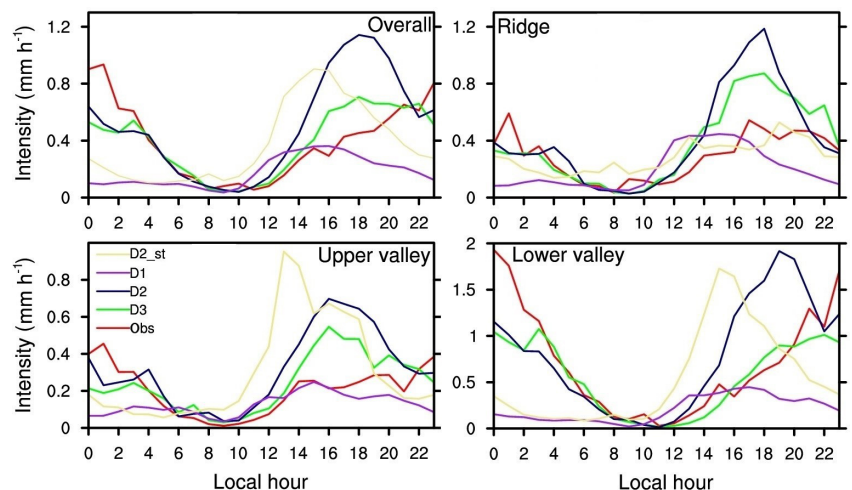

Figure 5. Diurnal precipitation during monsoon seasons at different WRF resolutions and observations, categorized into overall (all averages), ridge, upper valley, and lower valley.

as it could not adequately resolve the river valleys and ridges and the associated circulation characteristics due to its coarse resolution. In addition, convection parameterization is an- other potential source of uncertainty for this deficiency as relative improvement is noted in D2_st. It should also be noted that only the KF convection schemes is used in D1 and other scheme might perform better. D2 largely captures the diurnal precipitation pattern but substantially overestimates precipitation intensities, whereas D3 largely improves the simulation of the diurnal cycle and reduces the positive biases in precipitation intensities. Early precipitation, triggering a bias in the daytime peak in ridge and upper river valleys, decreases from D1 to D2 with further improvement from D3. In terms of magnitude, all domains in general overestimate the evening peak but underestimate the nocturnal peak consistent with Collier and Immerzeel (2015) and Norris et al. (2016). Higher overestimation in D2 than in D3 may be attributed to explicitly resolved convection over coarse grid cells, indicating that convection-permitting simulations at higher resolutions can further improve the model skill in reproducing the diurnal cycle characteristics, thereby eliminating the convection from a large area and better representing the entrainment process. Although D3 shows the best performance, with 


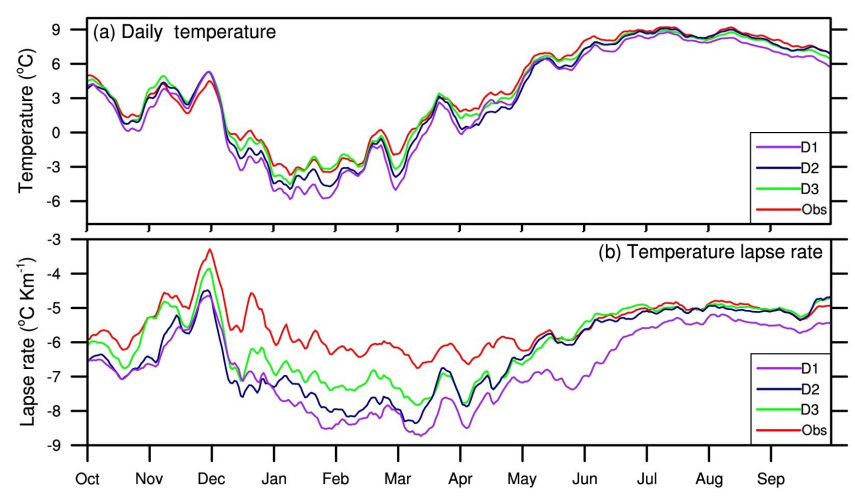

Figure 6. Daily station averaged (a) temperature and (b) its lapse rate at three WRF resolutions and observations (plotted as 10-day moving average).

closer agreement with observations and a better representation of the spatial and diurnal characteristics, there is still a deficiency regarding the narrow and deep upper valleys like Rolwaling, where mountains and valleys are not fully resolved in the 30 arcsec WRF topography. This is reflected by the relatively poor performance at upper-valley stations.

\subsubsection{Temperature}

Mean observed temperatures range from $-14^{\circ} \mathrm{C}$ in the highmountains in January to $21^{\circ} \mathrm{C}$ in the lowlands during the early monsoon (Fig. 6a).

The error statistics calculated for elevation-adjusted daily temperatures clearly show the best performance by D3 (followed by D2 and D1) in simulating the temperature, featuring low bias (warm or cold), smaller MAE, RMSE, RAR, and relatively higher $r$ against observations (Table 4). During the monsoon, D2 shows the same skill as D3. On utilizing monthly data for calculation, most error statistics show improvement in terms of biases. In general, all resolutions show a net cold bias in all seasons, except for D3 in the postmonsoon.

The observed seasonal cycle of temperature, with lowest temperatures in January and highest during monsoon months, has been reproduced well at all WRF resolutions and is also in good accordance with previous studies from Rolwaling (Gerlitz et al., 2016; Müller et al., 2016b). The cold bias is found during winter and the pre-monsoon season, which interestingly reduces with improving resolution from D1 to D3 (Fig. 6a). The best result for the highest resolution can be attributed to the better representation of topography and associated local circulation characteristics, which develop due to radiative surface heating and cooling and moisture processes in complex mountain terrain. On the other hand, the high cold bias during winter and the pre-monsoon may be linked to the overestimation of snowfall (precipitation) in high-altitude areas, since overestimated snow increases the surface reflectance and the limited avail- able net radiation is additionally utilized for snow melting (Immerzeel et al., 2014). This in turn reduces the sensible heat flux and ultimately the temperature in high-altitude regions. These cold-bias patterns attributed to wet bias in precipitation with snow cover, moisture, and evaporation feedbacks are consistent with those reported in mountainous regions of the greater European Alps (Haslinger et al., 2013).

The observed environmental lapse rates feature a bimodal distribution with maxima in the pre-monsoon and early postmonsoon and minima in early winter and in monsoon seasons (Fig. 6b). Specifically, the observed lapse rate varies from $-4.7^{\circ} \mathrm{C} \mathrm{km}^{-1}$ in November and December to above $-6.3^{\circ} \mathrm{C} \mathrm{km}^{-1}$ in March and April, with an annual average of $-5.6^{\circ} \mathrm{C} \mathrm{km}^{-1}$, consistent with previous studies (Kattel et al., 2013; Salerno et al., 2015). All WRF resolutions are able to broadly reproduce the bimodal distribution of lapse rates. Their magnitude during the monsoon months is relatively better reproduced, which is in agreement with the results of Gerltiz et al. (2016), who investigated the seasonal cycle of the ERA-Interim internal lapse rate over the Rolwaling Himal. However, simulated winter and spring season lapse rates are higher than observed ones. As with other statistics, the skill of D3 is superior to that of the D2 and D1 domains.

The distribution of temperature percentiles is reproduced remarkably by the WRF, irrespective of the domain resolution, particularly for the maximum temperatures (Fig. 7). The lowest percentiles of daily minimum temperatures, however, are highly underestimated during winter and the preand post-monsoon seasons due to cold biases simulated for such periods, with a relative improvement for high-resolution domains.

The observed annually averaged diurnal cycle features its minimum temperature in the early morning (at 06:00 LT) and its maximum temperature around noon which is earlier than the peak observed over low-elevation regions in the south of the target area (Fig. 8). The diurnal temperature variability is reproduced well by the WRF domains with a negligible delay. However, during the night and morning hours, simulated temperatures show a strong negative bias, particularly for D2 and D1, where the topography is significantly smoothed and topoclimatic processes are insufficiently captured. During afternoon and evening hours, the negative bias is replaced by a slight warm bias in all domains. As discussed earlier for other temperature characteristics, the diurnal cycle is best reproduced in the monsoon and post-monsoon, while winter and the pre-monsoon feature a higher cold bias.

Another noteworthy feature of the diurnal bias is the abrupt falling tendency towards a higher-magnitude negative bias between 09:00 and 10:00 LT, which is more distinct in D2 and D3 (where valley and mountain are resolved) during the post-monsoon and monsoon. 
Table 4. Seasonal error statistics (pooled data) based on monthly and daily average temperature. (Abbreviations are the same as in Table 3 for statistics that appear in both tables. Additional abbreviations are as follows: BIAS - WRF - Obs; MAE - mean absolute error).

\begin{tabular}{|c|c|c|c|c|c|c|c|c|c|}
\hline \multirow[t]{2}{*}{ Error statistics } & \multicolumn{4}{|c|}{ Based on monthly average temperature } & \multirow[b]{2}{*}{ Unit } & \multicolumn{4}{|c|}{ Based on daily average temperature } \\
\hline & Winter & Pre-monsoon & Monsoon & Post-monsoon & & Winter & Pre-monsoon & Monsoon & Post-monsoon \\
\hline BIAS_D3 & -0.36 & -0.34 & -0.33 & 0.31 & ${ }^{\circ} \mathrm{C}$ & -0.20 & -0.38 & -0.33 & 0.25 \\
\hline BIAS_D2 & -1.16 & -1.10 & -0.22 & -0.10 & ${ }^{\circ} \mathrm{C}$ & -0.93 & -1.03 & -0.23 & -0.07 \\
\hline BIAS_D1 & -1.94 & -1.44 & -0.78 & -0.45 & ${ }^{\circ} \mathrm{C}$ & -1.58 & -1.18 & -0.78 & -0.48 \\
\hline MAE_D3 & 1.50 & 1.09 & 0.62 & 1.04 & ${ }^{\circ} \mathrm{C}$ & 1.63 & 1.36 & 0.75 & 1.32 \\
\hline MAE_D2 & 2.03 & 1.49 & 0.58 & 1.33 & ${ }^{\circ} \mathrm{C}$ & 2.19 & 1.75 & 0.74 & 1.60 \\
\hline MAE_D1 & 2.55 & 1.83 & 1.02 & 1.64 & ${ }^{\circ} \mathrm{C}$ & 2.72 & 1.90 & 1.16 & 1.68 \\
\hline RMSE_D3 & 1.82 & 1.34 & 0.84 & 1.31 & ${ }^{\circ} \mathrm{C}$ & 2.08 & 1.73 & 1.03 & 1.70 \\
\hline RMSE_D2 & 2.75 & 1.88 & 0.72 & 1.90 & ${ }^{\circ} \mathrm{C}$ & 2.93 & 2.23 & 1.02 & 2.14 \\
\hline RMSE_D1 & 3.56 & 2.52 & 1.40 & 2.28 & ${ }^{\circ} \mathrm{C}$ & 3.69 & 2.70 & 1.59 & 2.29 \\
\hline RAR_D3 & 0.29 & 0.19 & 0.15 & 0.25 & & 0.32 & 0.24 & 0.18 & 0.31 \\
\hline RAR_D2 & 0.44 & 0.27 & 0.13 & 0.36 & & 0.44 & 0.32 & 0.18 & 0.39 \\
\hline RAR_D1 & 0.57 & 0.36 & 0.25 & 0.43 & & 0.56 & 0.38 & 0.28 & 0.41 \\
\hline$r \_\mathrm{D} 3$ & 0.98 & 0.99 & 0.99 & 0.97 & & 0.97 & 0.98 & 0.99 & 0.96 \\
\hline$r \_\mathrm{D} 2$ & 0.98 & 0.99 & 0.99 & 0.96 & & 0.96 & 0.98 & 0.98 & 0.95 \\
\hline$r \_\mathrm{D} 1$ & 0.97 & 0.99 & 0.99 & 0.95 & & 0.95 & 0.98 & 0.98 & 0.95 \\
\hline
\end{tabular}

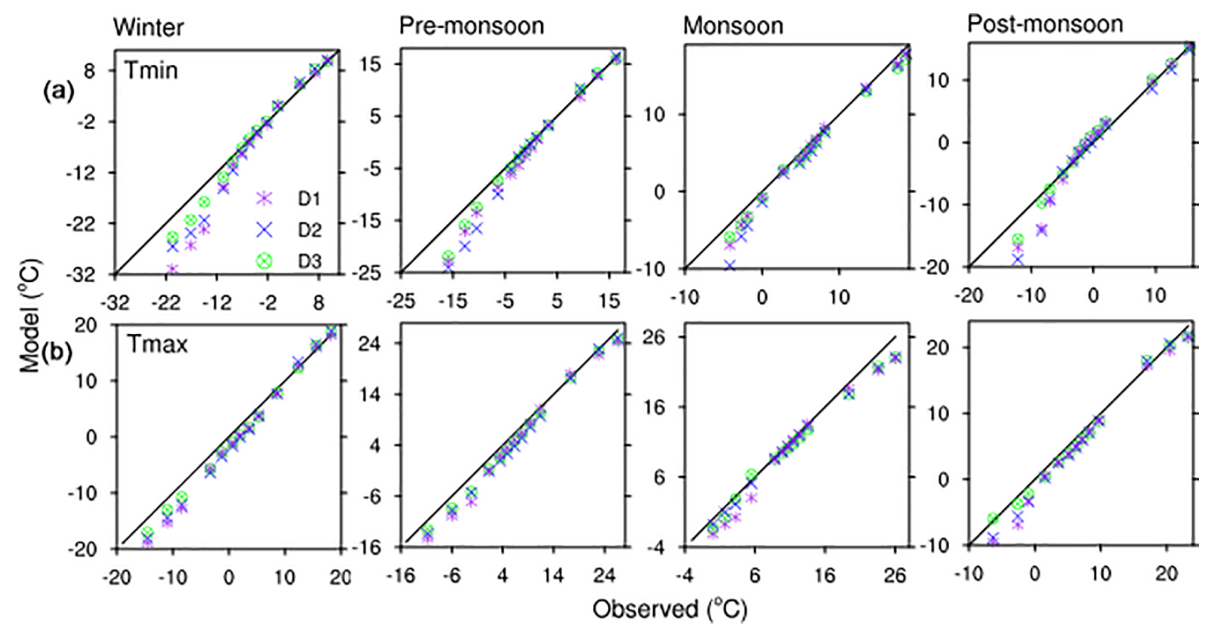

Figure 7. Percentile value comparison for daily minimum (Tmin, a) and maximum temperature (Tmax, b) (1, 5, 10, 20, 30, 40, 50, 60, 70, $80,90,95$, and 99 percentiles) at three WRF resolutions with observations for four different seasons.
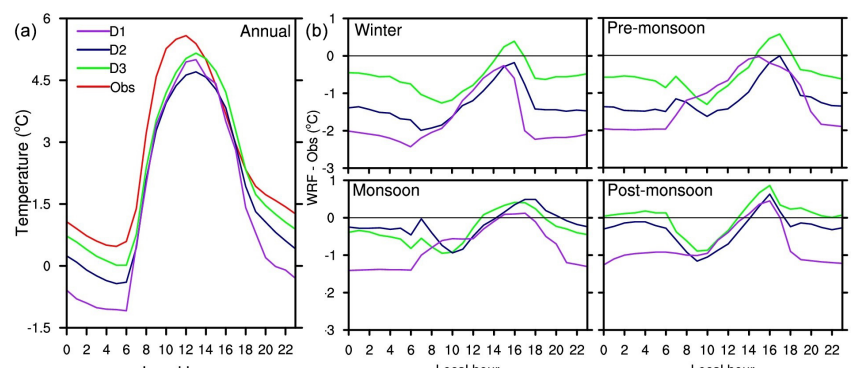

Local hour

Local hour

Figure 8. Diurnal mean annual temperature (a) and biases of temperature in all four seasons (b) at three WRF resolutions.

\subsection{Seasonal and spatial distribution of surface variables}

Extensive validation of WRF-simulated surface variables against station observations in terms of several measures suggests a satisfactory skill of higher-resolution simulations, particularly of D3. Here, we report on the spatial distribution of simulated surface variables across different seasons. Since the skill of D2 is roughly comparable to that of D3, we further assess the spatial distribution of surface variables over the wider domain of D2.

Winter precipitation is associated with western disturbances, which mainly influence the western Himalayas but occasionally reach the study region, developing a northsouth gradient. Such a gradient is generally captured by all 


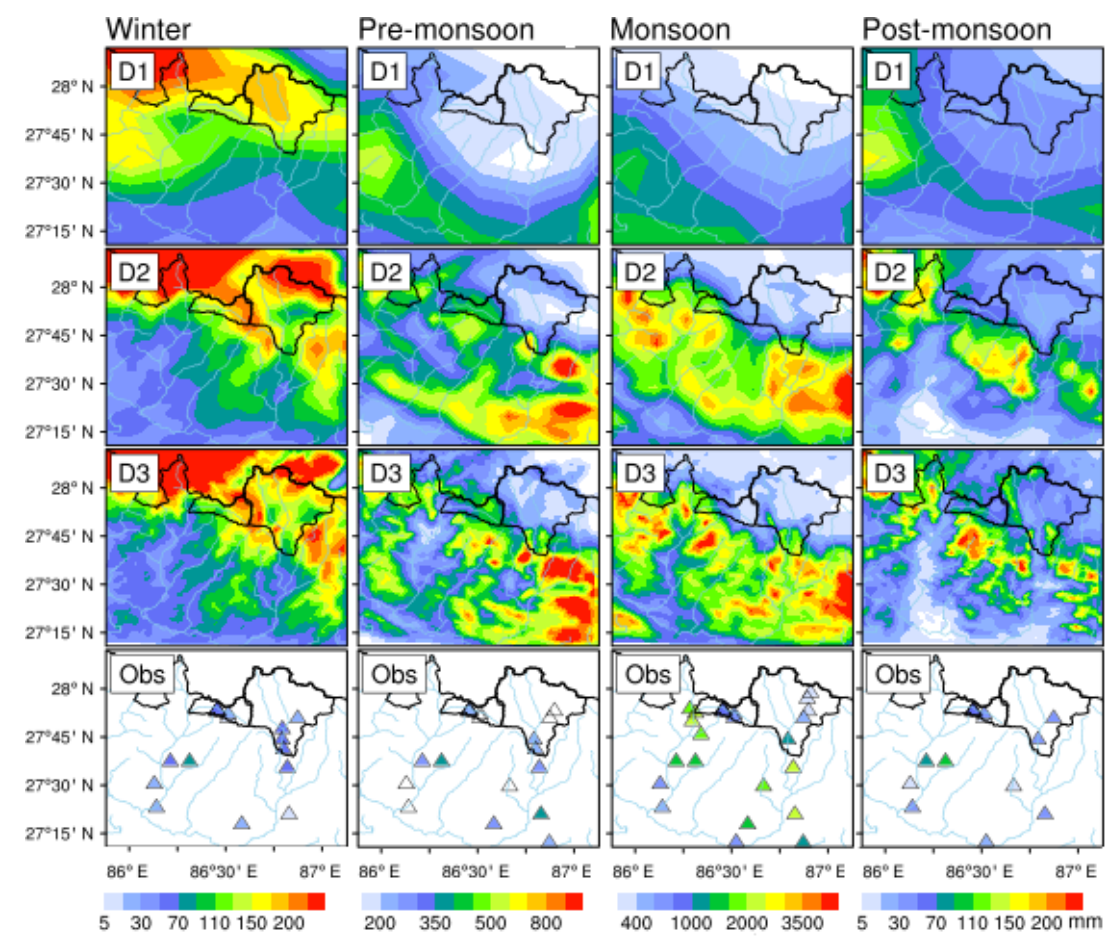

Figure 9. Spatial distribution of seasonal total precipitation at three WRF resolutions (D3, D2, and D1) and observations, with rivers in the Nepal region delineated in light blue and the political boundary of Nepal and the Khumbu (right) and Rolwaling (left) catchment boundaries given in black.

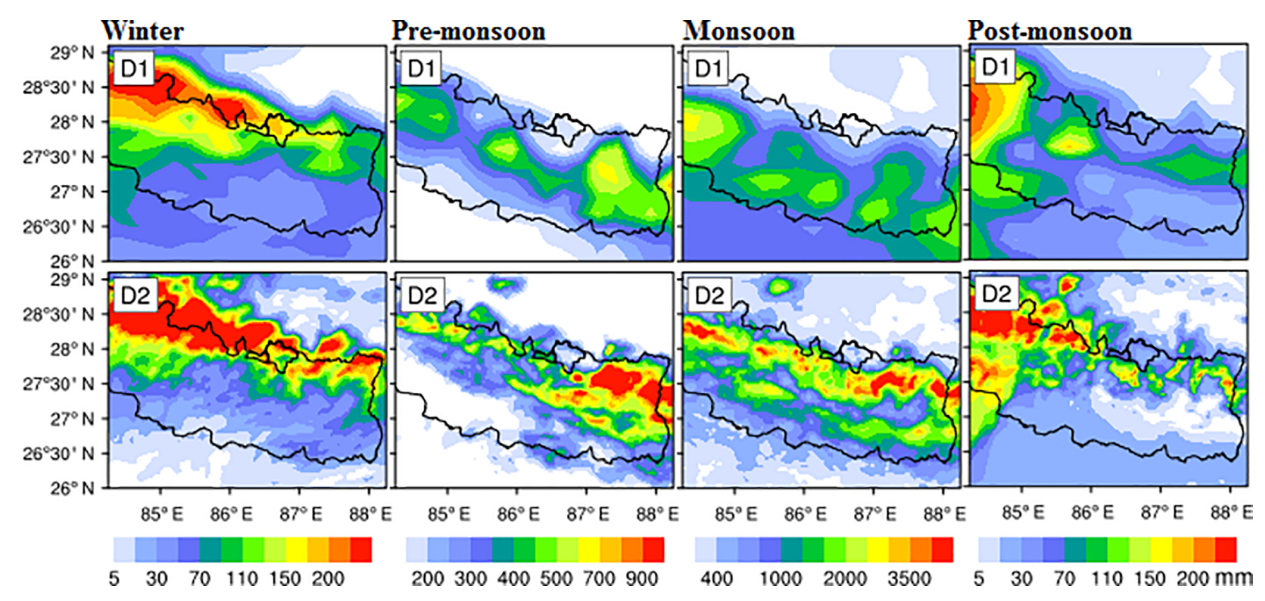

Figure 10. Seasonal distribution of precipitation in larger area in D2 and D1 domain resolutions.

WRF resolutions (Fig. 9). However, the drier Rolwaling and Khumbu valleys and the distinct precipitation gradients between valleys and tops are only captured by higher resolutions (D2 and D3), whereas D1 features a smoothed, evenly distributed precipitation pattern. D3 and D2 simulate twice as much precipitation over the ridges as over the valleys. Additionally, although both D2 and D3 have a similar spatial pattern, precipitation is more concentrated over mountain tops for D3 than for D2, indicating a more realistic altitudinal representation of the spatial pattern. Nevertheless, winter precip- itation is overestimated over the southern Himalayan slopes, the upper valleys, and mountain tops in all WRF domains. Such an overestimation mainly arises from a few events of westerly disturbance, whose intensities are overestimated in all WRF simulations as depicted in Fig. 3. All WRF domains indicate a west-east gradient of winter precipitation, which is more clearly depicted by the larger D2 domain (Fig. 10). Overall, the distribution pattern of winter precipitation and its overestimation is congruent with previous studies (Seko, 
1987; Putkonnen, 2004; Norris et al., 2016; Collier and Immerzeel, 2015).

Pre-monsoon precipitation over the study region is primarily generated by localized convective instability (due to local surface heating and uplifting) with moisture supply from local sources (Shrestha et al., 2012) or by the occasional passage of westerly disturbances during early months. However, due to the location of the target area in eastern Nepal, a substantial amount of precipitation occurs in the late premonsoon season, when moisture supply from the Bay of Bengal starts to increase. Thus, the combination of all of these features results in an east-west and altitudinal gradient of precipitation during the season. D1 underestimates premonsoon precipitation over Rolwaling, Khumbu, and their adjacent southern areas, while it overestimates precipitation over the southern Himalayan slopes. D2 overestimates precipitation roughly over the whole domain and smoothly capture the mountain-top and valley-bottom contrast. This contrast (drier valleys but slightly moist slopes and ridges) is reproduced well by the D3 simulation only. In the larger D2 domain, the pattern of the east-west precipitation gradient is depicted clearly (Fig. 10).

During the monsoon season, micro- or mesoscale convective processes take place due to intricate interactions of the synoptic weather systems with the complex topography, responsible for producing an extremely heterogeneous spatial distribution of precipitation (Seko, 1987; Norris et al., 2015). Such a pattern is simulated well by all WRF resolutions (Fig. 9), but in D1, a smoothed pattern like in other seasons and substantially underestimated precipitation are simulated. Unlike D1, higher-resolution simulations are able to resolve the precipitation contrast between valleys and mountain slopes and ridges. For instance, low precipitation $(<800 \mathrm{~mm})$ at Manthali and Mane Bhanjyang stations in the lower river valley is completely absent in D1, while it is reproduced well by D2 and D3. Similarly, high-precipitation pockets observed at Gumthang (northwest of D3) (Karki et al., 2017) as well as precipitation sums in the order of $2000 \mathrm{~mm}$ at stations Bhalukhop and Aiselukharka (on the mountain slopes) are resolved in D2 and D3 only. Further, for the Rolwaling Khola watershed and the Khumbu region in the north of the high mountain ranges, the observed negative altitudinal gradient is evident in both D3 and D2 simulations, while D1 fails to simulate this mesoscale feature. For example, observed precipitation at the lower-valley station of Phakding in the Khumbu region is in the order of $1000 \mathrm{~mm}$, while it drops by one-third upstream at Phiriche and Pyramid stations. Likewise, in the Rolwaling Khola watershed, precipitation at the basin outlet and over the surrounding areas is around $2000 \mathrm{~mm}$ and sharply drops to one-fifth upstream.

Although the spatial patterns are broadly similar between D2 and D3, owing to a more realistic representation of topography, the mountain-valley precipitation contrast is better resolved in D3. Further, the reduced positive precipitation bias for lower river valleys in D3 compared to D2 is clearly discernable. Over the larger D2 domain, simulated precipitation features two maxima zones: (1) a narrow peak precipitation band along the first mountain barrier and (2) a relatively broader peak precipitation band at the southern slopes of the Himalayan range (Fig. 10). The river valleys between these two zones are found to be relatively drier. Such a pattern is in agreement with the station observations (Karki et al., 2017), satellite-derived observed estimates (Bookhagen and Burbank, 2006; Shrestha et al., 2012), and simulations (Maussion et al., 2014; Gerlitz et al., 2015). Unlike D2, D1 fails to capture such a spatial pattern, primarily due to the poor representation of topography, as topography, which plays an important role in developing localized convective activity and orographic precipitation, is not represented well on a coarser grid scale. In addition, uncertainties in convection parameterization can amplify these deficiencies. The topographic controls on precipitation distribution are further supported by the D2_st simulation, which, although it shows improvement over D1, also fails to capture the double precipitation maximum zones owing to its poor topographic representation (Fig. S2).

The post-monsoon is the driest season over the study region, for which the spatial distribution is reproduced well by WRF; however, this is done with an overall overestimation (Fig. 9). Interestingly, map of D2 and D1 with a larger aerial coverage shows a west-to-east gradient, which is in contrast to the observed east-to-west gradient (Fig. 10). This contrasting pattern may be linked to a rare heavy snowfall event in the Annapurna region of the Nepalese Himalayas between 13 and 15 October that resulted from the collision of a westerly trough with the remnants of the tropical cyclone Hudhud, which formed over the Bay of Bengal (Wang et al., 2015). As shown in Fig. 11, individual station biases show a mixed pattern of wet and dry bias, with an improvement in D3 resolution compared to D2.

Summarizing, explicitly resolved convection (eliminating convection parameterization deficiencies and model dynamics) together with the better representation of the modeltopography with an increasing horizontal resolution reproduces the interplay of the large-scale circulation with the topography better, which results in an improved simulation of localized convective precipitation, orographic precipitation, and thus an amendment of the spatial precipitation pattern.

For temperature, the skill of WRF in simulating the spatial distribution is restricted by the degree of the representation of real topography by the considered resolutions, where a coarser resolution shows a smoothed pattern, while a finer resolution resolves spatial variability (Fig. 12). Winter temperatures vary from less than $-30^{\circ} \mathrm{C}$ at higher Himalayan mountain tops to above $+20^{\circ} \mathrm{C}$ in the southern river valleys. These pattern are realistic, but limited observations (mostly in river valleys) do not represent the temperature on high mountains, as resolved by WRF. The spatial distribution of temperature is broadly similar in all seasons, with only a change in the range of temperature between high- and low- 


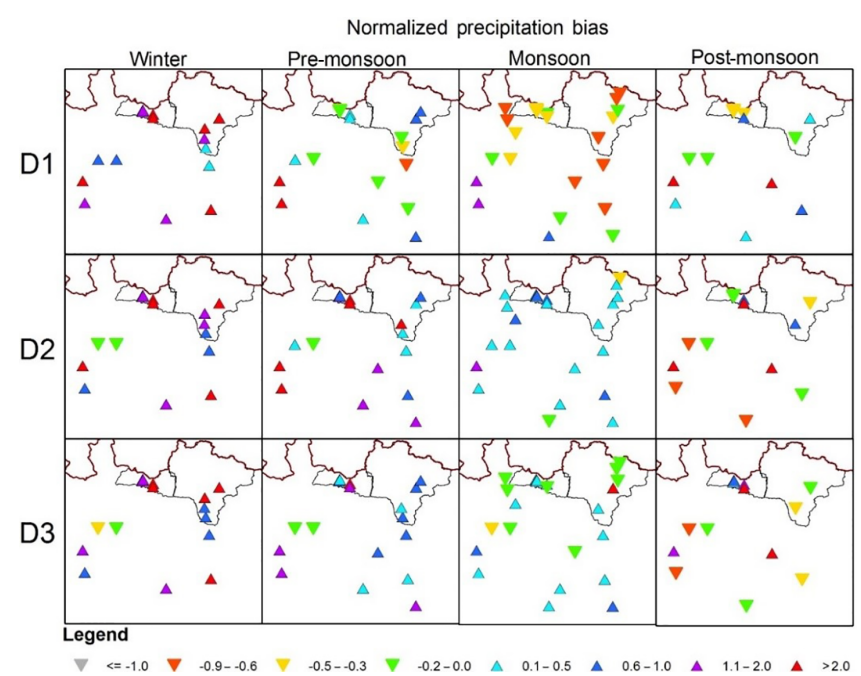

Figure 11. Station-wise normalized bias [(WRF-Obs)/Obs] of precipitation for three WRF resolutions for all four seasons zoomed over station location only.

altitude stations. There is a cold bias in pre-monsoon and winter temperatures in all three domains with the largest magnitude for the coarse D1 domain. The improvement (reduction of the cold bias) with respect to finer resolutions can be clearly seen in Fig. 6a. Fine resolutions represent the topography and the local land surface features better, allowing the model to resolve the associated physical processes and their interaction with the atmospheric circulation better. Overall the cold bias simulated for winter temperatures (Table 4) over the study area is generally dominated by the cold bias from the upper-valley stations, as lower-valley stations mostly feature a warm bias (Fig. 13). In contrast to other seasons, the warm biases evident at lower river valley station locations reverse to cold during monsoon season at high resolutions, which can potentially be associated with wet bias in precipitation (Fig. 11) in those places with moisture and evaporation feedbacks, as discussed earlier.

\subsection{Altitudinal gradients of surface variables}

The altitudinal distribution of spatially mean winter precipitation shows a peak of about $275 \mathrm{~mm}$ at an elevation of 5000 ma.s.l. at both D3 and D2 resolutions, while lower river valleys $(\sim 500 \mathrm{~m}$ a.s.l.) experience lowest precipitation of $50 \mathrm{~mm}$ (Fig. 14). In D1, the altitudinal dependency is completely lacking for all seasons. The altitude of simulated peak winter precipitation is in agreement with the observations and with other modeling studies over Nepal and the Himalayas (Seko, 1987; Putkonnen, 2004; Collier and Immerzeel, 2015; Norris et al., 2016).

In contrast to the winter precipitation peak at $5000 \mathrm{~m}$ a.s.l., the peak monsoonal precipitation of $\sim 2700 \mathrm{~mm}$ is simulated at around $3000 \mathrm{~m}$ a.s.l. by D3 and at slightly lower elevations

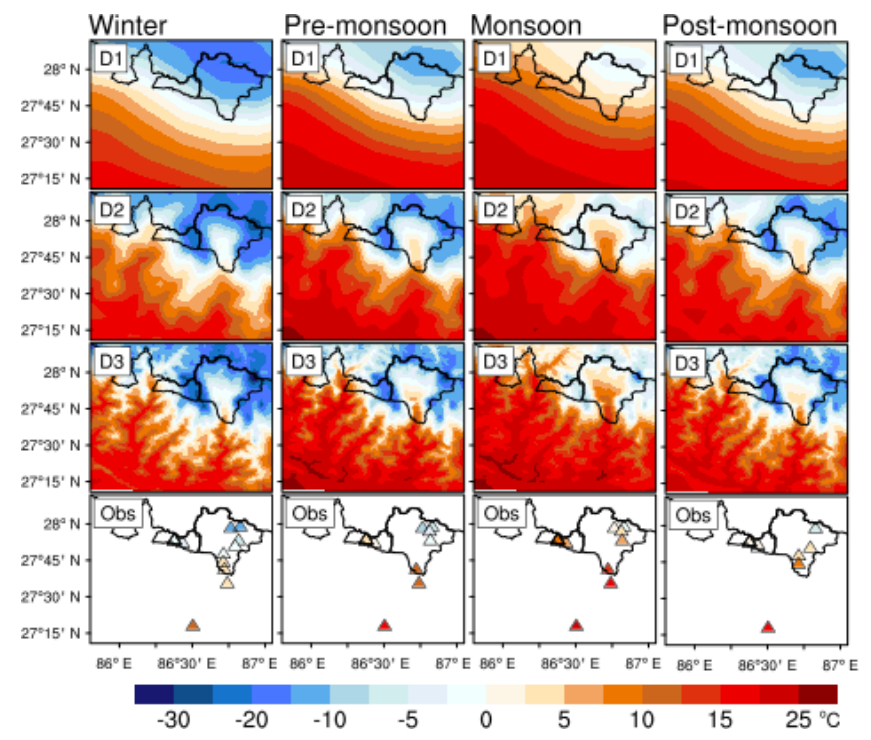

Figure 12. Spatial distribution of temperature $\left({ }^{\circ} \mathrm{C}\right)$ for four seasons at three WRF resolutions and observations.

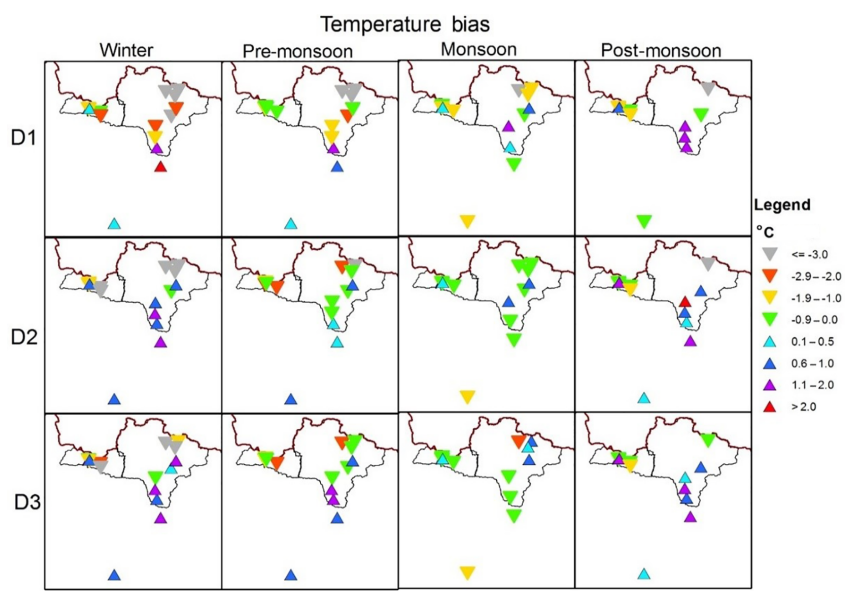

Figure 13. Station-wise seasonal bias in temperature $\left({ }^{\circ} \mathrm{C}\right)$ in all four seasons for three WRF resolutions zoomed over station locations only.

by $\mathrm{D} 2$. The precipitation sharply decreases both in higherand lower-altitudinal belts. D1 fails to reproduce the characteristic precipitation gradient. Compared to D3, D2 overestimates precipitation below $3000 \mathrm{~m}$ a.s.l., which may be linked to the development of wider convective cells along the windward slopes of the mountain ranges. The altitudinal gradient of monsoonal precipitation is consistent with the observed gradient and the precipitation peak around $2500 \mathrm{~m}$ a.s.l. over the whole Kosi Basin (Salerno et al., 2015). Putkonen (2004) reported an elevation of peak monsoonal precipitation over the Marsyangdi River basin in western Nepal at $3000 \mathrm{~m}$ a.s.l. Miehe (1990) detected a monsoonal precipitation peak between 3000 and $3600 \mathrm{~m}$ a.s.l. for the southern slopes of the Jugal Himalayas, located in the west of our study area. More- 

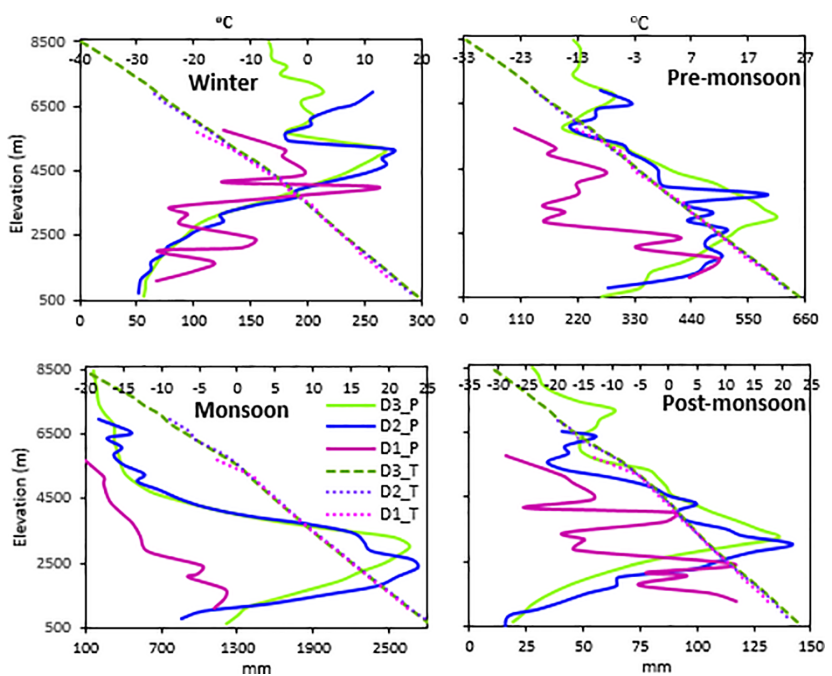

Figure 14. Altitudinal variation in precipitation and temperature at three WRF resolutions for all four seasons (over D3 area region only); the abbreviation are D1, D2, and D3 for the three domains, with $P$ (precipitation) and $T$ (temperature).

over, WRF (Collier and Immerzeel, 2015; Norris et al., 2016) and statistically based downscaled datasets (Gerlitz et al., 2015) also report similar altitudes for peak monsoonal precipitation over different regions of Nepal. The pre-monsoon and post-monsoon peak altitude is found in a similar altitudinal range as during the monsoon.

As discussed earlier, winter precipitation is affected by a few extratropical cyclones (western disturbances), which are often formed in association with upper-tropospheric Rossby waves. In these systems, warm and moist air masses are pushed upward by cold and dry air masses from the surface (frontal circulations). The additional uplift, which is necessary for the generation of precipitation in mountains, is dynamically caused by cross-barrier flows. In contrast, monsoonal systems, being convective in nature and originating from the surface, have a lower vertical extent than extratropical systems (see variable PBL in Fig. S1). Thus, the seasonal contrast in peak precipitation elevation between winter and summer is a direct result of the interplay of characteristic large-scale circulation mechanisms and the local-scale topography of the target region.

The altitudinal variation in temperature is found to be similar at all three resolutions with minor differences. The average lapse rates (entire grid considered without altitude correction) calculated over the D3 region for winter and the premonsoon, monsoon, and post-monsoon seasons are 7.4, 7.3, 5.6, and $6.8^{\circ} \mathrm{C} \mathrm{km}^{-1}$, respectively. Higher winter and premonsoon lapse rates from D3 are most probably affected by the cold bias observed over the upper-valley regions, which is even higher for the coarser resolutions. The seasonal differences in lapse rates can be attributed to changes in humidity. The shallower lapse rate observed during the mon- soon results from the condensation in the middle atmosphere (with abundant moisture availability) that releases latent heat, thereby warming the higher mountain ranges (Kattel et al., 2013; Immerzeel et al., 2014). In addition, cloud cover can negatively influence the lapse rate (Kattel et al., 2013), since higher cloud coverage reduces the radiative energy causing shallower lapse rates.

\subsection{Diurnal precipitation characteristics}

Spatial maps of peak precipitation timing clearly show the capability of the D3 resolution in simulating the observed contrast in diurnal characteristics between the river valleys and the mountain slope/ridges (Fig. 15). Though D3 accurately captures the midnight peak evident in the deep and wider river valleys of Khumbu, it still has deficiencies in representing the nocturnal peak precipitation observed in the narrow river valley of Rolwaling. D2 reproduces the general diurnal contrast between river valleys and ridges; however, the nighttime peak over the river valleys is shifted to late evening. In contrast, D1 fails to simulate any difference between river valleys and slopes/ridges, as noted earlier. Threehourly precipitation suggests that evening peak precipitation in ridge locations shifts more towards midnight and morning hours in river valley locations in D3 (Fig. 16). D2 triggers late evening peaks in river valley locations, while D1 has afternoon peaks. The underestimation of the nighttime peak but overestimation of the daytime peak magnitude is consistent with Norris et al. (2016), but our findings provide impressive evidence to suggest the capability of a kilometer-scale simulation in better resolving the diurnal peak timings within the river valleys.

As described earlier in previous studies based on the Tropical Rainfall Measuring Mission satellite-estimated precipitation data (Bhatt and Nakamura, 2006; Sahany et al., 2010; Shrestha and Desar, 2014), the midnight to early morning precipitation peak is observed over the southern foothills of the Himalayas. This large-scale feature is reproduced well by $\mathrm{D} 2$, while at the D1 resolution, only evenly distributed afternoon to evening peaks are noticed (Fig. 17). D2_st, even with its coarse topography $(\sim 20 \mathrm{~km})$, resolves this largescale features to some extent with the impact of explicitly resolved convection, and as a result of relatively less heterogeneous terrain in south, but the mountain-valley contrast simulated for our study area is very unrealistic compared to D2 (Fig. S2).

Three-hourly precipitation over the large D2 domain clearly shows the skill of convection-permitting WRF simulations in simulating the shift of the afternoon/early-evening peak over high mountains to midnight/early morning over wide river valleys and the foothills of the Himalayas, consistent with earlier reports (Bhatt and Nakamura, 2006; Shrestha and Desar, 2014; Norris et al., 2016). D1 however triggers early convection (12:00-15:00 LT) only. The shift in the hours of the lull in precipitation from morning 


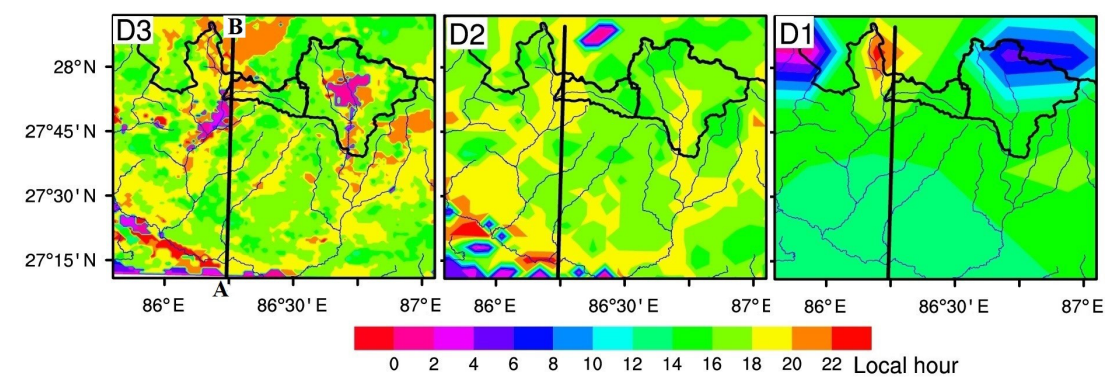

Figure 15. Peak precipitation hour (local time) simulated by three WRF resolutions. Rivers in the Nepal region are also delineated, with the political boundary of Nepal and Rolwaling (left) and Khumbu (right) catchment boundaries shown in black. Section AB is also drawn.
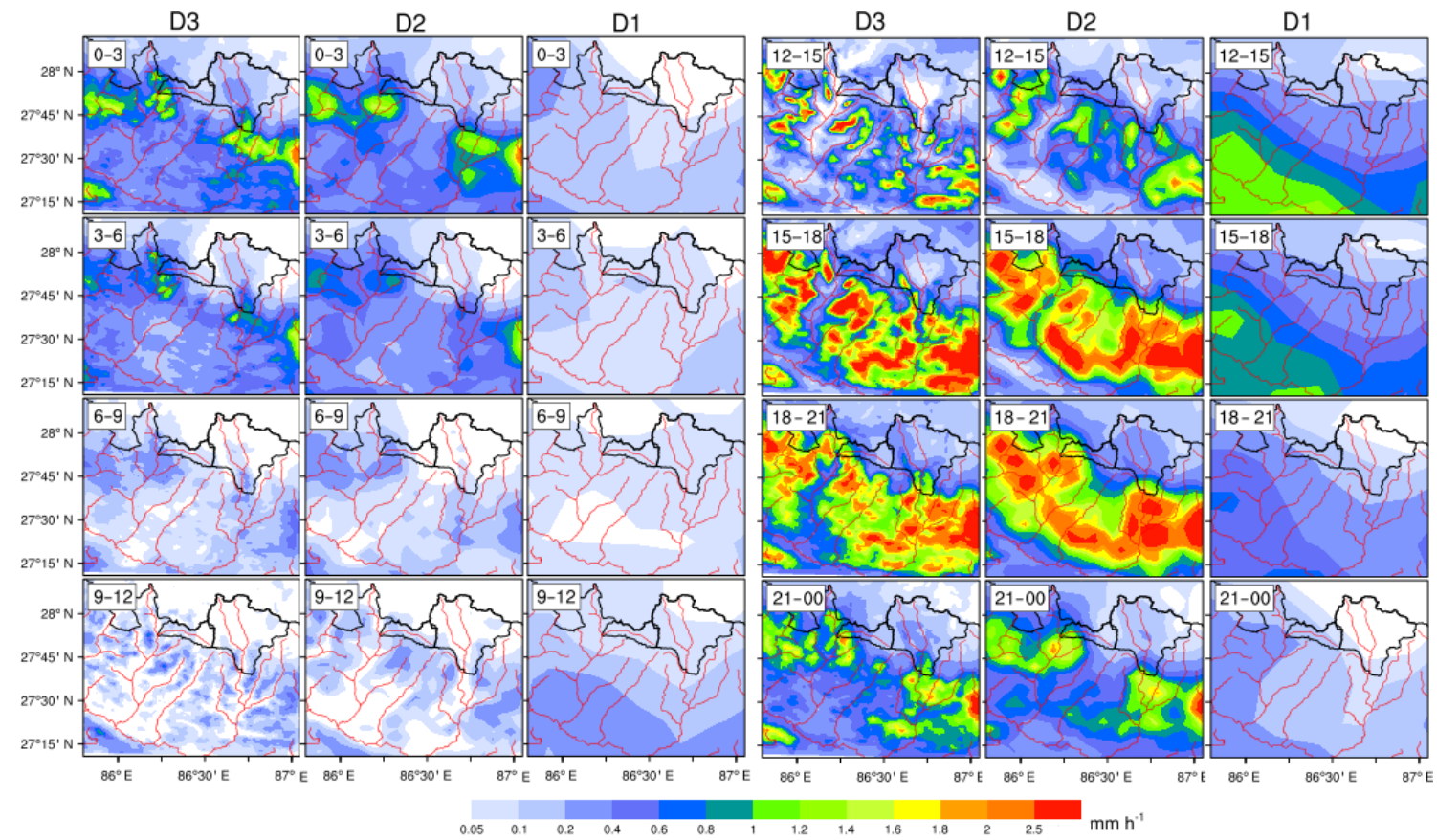

Figure 16. Spatial distribution of three-hourly (local time) average precipitation $\left(\mathrm{mm} \mathrm{h}^{-1}\right)$ plot during the monsoon season for three different WRF resolutions. Rivers in the Nepal region are delineated in red, and Rolwaling (left) and Khumbu (right) are overlaid in black.

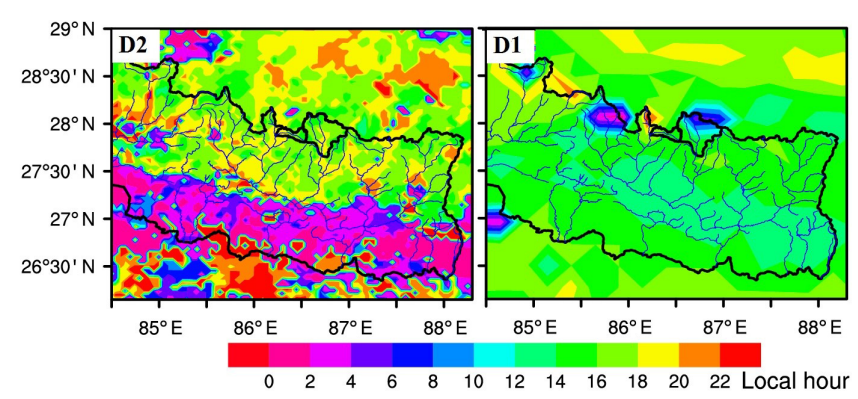

Figure 17. Spatial pattern of peak precipitation hours (local) during the monsoon season in a large area of D2 and D1. to day hours from north to south can also be clearly observed (Fig. 18). These features are further supported by the plotted surface $(10 \mathrm{~m})$ winds. From 09:00 until 18:00 LT, the surface wind plot shows the diversion of a southeasterly warm monsoonal flow towards the Himalayan mountain range, which results in an orographic uplift accompanied by labilization of the atmosphere. The model is capable of simulating both the strong vertical ascent of air masses over the mountain ranges (see Fig. 19) and the consequential monsoonal precipitation (Fig. 18). After 18:00 LT, the flow over the mountain valleys reverses. The high mountain regions are dominated by a northerly flow, which follows the direction of the major Himalayan valleys and might be interpreted as nocturnal drainage of cold air. The cold air converges with the monsoonal current over the Himalayan foothills, which leads to 


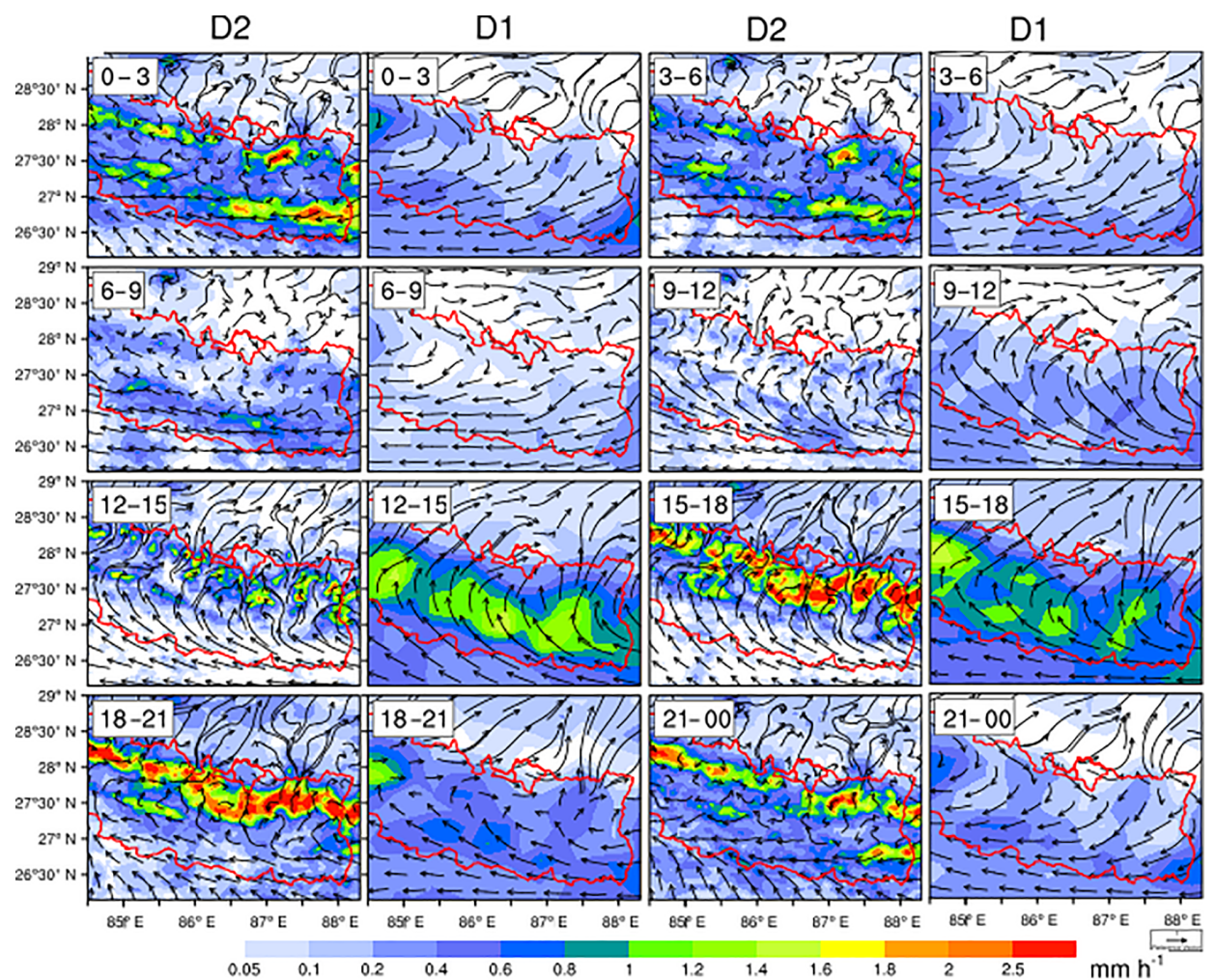

Figure 18. Spatial distribution of monsoon season three-hourly (local time) average precipitation (mm $\mathrm{h}^{-1}$ ) in a large area of D2 and D1 with surface wind $(10 \mathrm{~m}$ ) vectors overlaid; the political boundary of Nepal is given in red, with the Khumbu and Rolwaling catchments in the north.

the development of deep convection and the associated nocturnal precipitation peak.

Summarizing, D2 can resolve the large-scale nighttime peak as observed over the foothills and wider river valleys but has limited skill in fully reproducing the valley-based nocturnal peak in the study region. D3 substantially improves the results, providing an almost realistic representation of the shape of the diurnal precipitation cycle and its peak timing within river valleys. Nevertheless, sub-kilometer-scale simulation seems to be needed to resolve the topography and thus the diurnal features in narrow river valleys.

\subsection{Mountain-valley circulation}

Over the mountain tops and ridges, strong daytime heating in combination with moist monsoonal winds yields strong convection and associated precipitation during the afternoon, while the valleys are characterized by dry conditions. On the other hand, nocturnal peak precipitation, evident first in the lower river valleys and then over the southern foothills, is associated with the convergence of cold down-valley winds from radiatively cooled high mountains and the warm and moist monsoonal flow (Higuchi et al., 1982; Barros and Lang, 2003). Additionally, cold-air pooling might cause a pronounced nighttime precipitation peak in lower river val- leys (Gerlitz et al., 2016). The three-hourly averaged vertical wind speed plotted along the cross section AB (Fig. 19) clearly demonstrates the skill of D3 and to some extent of D2 in reproducing the characteristics of mountain-valley circulation, mainly owing to a better representation of mountain slopes, ridges, and valleys. In contrast, D1 fully fails to reproduce such circulation characteristics, which is mainly responsible for reproducing the diurnal cycle of precipitation. For D1, convection parameterization-related deficiencies are further responsible for this failure to some extent. In D3 and D2, very strong convective activity (high positive vertical velocity as proxy) on the mountain slopes and ridges occurs from late afternoon to the evening hours. This convective activity weakens in the late evening and is replaced by subsidence during the night. The convergence of cold valley winds with the monsoonal flow results in a nighttime precipitation peak over the river valleys. It is to note that the D3 topography resolves many river valleys and ridges that are not evident in D2; thus, the resultant steeper terrain yields more realistic strong and narrower (daytime) updrafts and (nighttime) downdrafts. As discussed in the previous section, this improved representation of the mountain-valley circulation produces realistic nighttime peaks over river valleys such as Khumbu and the lower reaches of Rolwaling in D3, which is not fully represented in D2. However, the lack of strong 


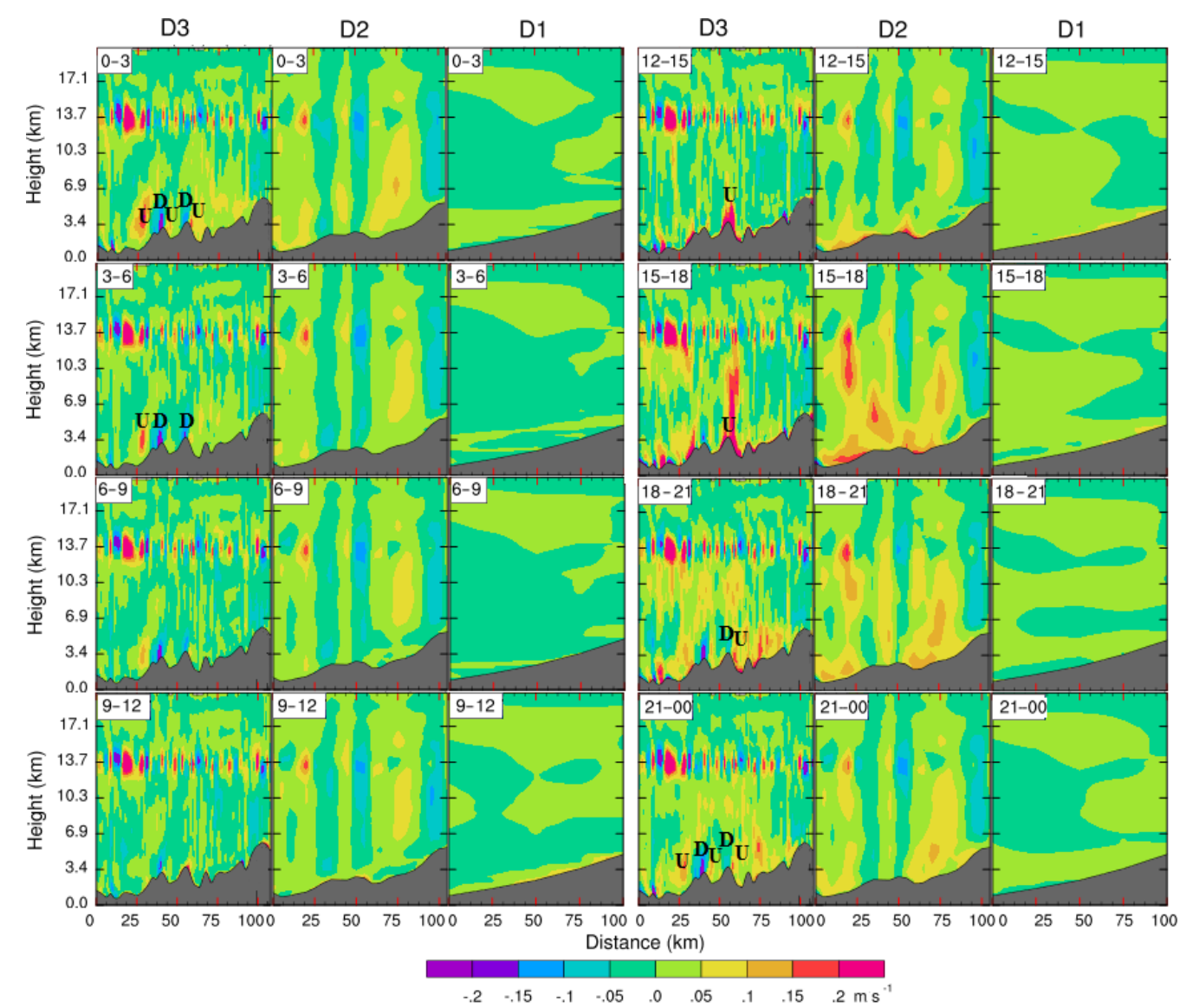

Figure 19. Three-hourly (local time) monsoon season average vertical velocity $\left(\mathrm{m} \mathrm{s}^{-1}\right)$ at all three resolutions along the $\mathrm{AB}$ section, with topography in gray. A few points of upward and downward flows are also marked as $\mathrm{U}$ and $\mathrm{D}$, respectively.

nighttime convergence overall leads to underestimated precipitation as noted by Norris et al. (2016). This may be due to (1) too much release of moisture on the mountain slopes during the day (anomalously strong convection) and (2) an underestimation of down-valley winds due to smoothed topography.

Overall, it is found that an adequate simulation of the diurnal cycle in the model is directly linked to adopting higher resolutions with explicit convections, owing to their better representation of real topography and associated microphysical processes of the mountain-valley circulation, entrainment process, insolation, and explicit treatment of convection.

\section{Conclusions}

This study uses 1 year of WRF simulation in three nested domains of 25 (non-convection-permitting), 5 , and $1 \mathrm{~km}$ (convection-permitting) horizontal grid spacing over a highly structured Himalayan target area in order to investigate the impact of model resolutions on reproducing the seasonal and diurnal characteristics as well as the spatial pattern of temperature and precipitation.
The overall evaluation of the WRF (using a network of high-altitude and low-altitude stations) clearly demonstrates the added value of high over coarse resolutions for both surface parameters, not only in terms of spatial pattern but also in terms of magnitude, seasonal cycle, and diurnal characteristics. The better representation of topographic features in high-resolution WRF runs together with explicitly resolved convection allows the realistic simulation of the mountainvalley circulation (convection), microphysical processes, and other local-scale processes and leads to an improved representation of the surface variables. The better simulation of monsoonal precipitation and temperature, which are strongly influenced by the mesoscale mountain-valley circulation, further confirms this. Although the essential features in both 5 and $1 \mathrm{~km}$ convection-permitting simulations are the same, the latter reduces the overestimated magnitude of precipitation and biases in temperature and, in particular, reproduces the timing and magnitude of monsoonal diurnal cycle of precipitation better, indicating the dominant influence of topography and surface fields (atmospheric dynamics) on resolving the topoclimates. Therefore, this assessment shows the potential of WRF high-resolution (convection-permitting) 
simulations for climate impact studies, environmental applications, and investigations of the interplay between synoptic weather systems and local topography. The better simulation further shows the appropriateness of WRF for future climate projection in the region. However, these conclusions are based on only 1 year of simulation and need to be further validated by means of longer-term modeling studies. Further, for deep and narrow river valleys, a sub-kilometer-scale simulation with higher resolution of land use, land cover, and topographic data is needed to fully resolve microclimatic features. It is worth mentioning that (sub)-kilometer-scale simulations for larger areas are computationally very expensive; however, as mentioned earlier, slightly coarser (but still convection-permitting) WRF simulations (with $5 \mathrm{~km}$ spatial resolution) capture the essential features of precipitation and temperature over the complex target area. A modeling chain, including dynamical downscaling of climate model results and subsequent statistical downscaling and terrain parameterization approaches (as proposed in Gerlitz et al., 2015) to kilometer and sub-kilometer-scale, might be a feasible option for the region. The main findings of this study are summarized as follows.

- Overall, day-to-day variation and hourly features of precipitation and temperature are better simulated by highresolution simulations (value added) with a more realistic representation of magnitude during the dominant monsoon season than in other seasons.

- Precipitation in the $25 \mathrm{~km}$ simulation is underestimated and the spatial pattern is unrealistic; in particular the contrast between mountains and valleys is not adequately represented. Both 5 and $1 \mathrm{~km}$ simulations broadly reproduce these features, but owing to a better representation of topography in $1 \mathrm{~km}$, the mountainvalley precipitation contrast is better resolved in the latter. Further, the overestimation of precipitation in the $5 \mathrm{~km}$ simulation is highly reduced in the $1 \mathrm{~km}$ run, with a better representation of intense precipitation events.

- The altitudinal dependency of precipitation at high resolutions shows peak precipitation at around $5000 \mathrm{~m}$ a.s.1. during the winter season and $\sim 3000 \mathrm{~m}$ a.s.l. during the monsoon season, which is in agreement with observations. The low-resolution domain completely fails to simulate the elevational gradient of precipitation.

- The representation of the characteristic diurnal cycle of precipitation over the target region is simulated impressively well by the high-resolution domains with explicitly resolved convection, while the low-resolution domain does not reproduce the nocturnal maxima over mountain valleys and the Himalayan foothills. The $5 \mathrm{~km}$ resolution domain shows a distinct nocturnal maximum of monsoonal precipitation over broad valleys and foothills only, which can be attributed to the convergence of down-valley winds with the monsoonal flow.
The $1 \mathrm{~km}$ domain substantially improves the results, providing an almost realistic representation of the shape of the diurnal precipitation cycle and its peak timings in river valleys. Nevertheless, sub-kilometer-scale simulation seems to be needed to resolve the topography and associated topoclimatic processes in very narrow river valleys.

Data availability. Station observations utilized in this study are available from the Department of Hydrology and Meteorology (Nepal), EvK2CNR (Italy), the TREELINE project of the Institute of Geography, University of Hamburg, and the Chair of Soil Science and Geomorphology, University of Tübingen (Germany), and Laboratoire Hydrosciences (CNRS, IRD, Université de Montpellier, France); these can be obtained upon request. Model output used in this study can be provided by the author upon request. The ERA-Interim dataset is freely available from ECMWF website (www.ecmwf.int).

\section{The Supplement related to this article is available online at https://doi.org/10.5194/esd-8-507-2017-supplement.}

Competing interests. The authors declare that they have no conflict of interest.

Acknowledgements. The ERA-Interim dataset is freely available from ECMWF. The authors would like to thank the Department of Hydrology and Meteorology (Nepal), EvK2CNR (Italy), the TREELINE project of the Institute of Geography, University of Hamburg, and the Chair of Soil Science and Geomorphology, University of Tübingen (Germany), and Laboratoire Hydrosciences (CNRS, IRD, Université de Montpellier, France) for providing the meteorological data. In particular, the support of Johannes Weidinger, Pierre Chevallier, Gian Pietro Verza, and Dibas Shrestha during data acquisition and the support and suggestions of Lindsey Nicholson, Emiley Collier, and Eleonore Schenk in data interpretation and model setup are greatly acknowledged. Further, we are grateful to Meghanath Dhimal and Bodo Ahrens and his teams for their suggestions and input on preliminary results. Ramchandra Karki's PhD scholarship was supported by the Deutscher Akademischer Austauschdienst (DAAD) under the research grants for doctoral programmes in Germany through the University of Hamburg, Germany. We are also grateful to the Regional Computing Centre (RRZ) of the University of Hamburg and the German Climate Computing Centre (DKRZ), Hamburg, for providing the computing resources for the simulations. Further, we acknowledge the TREELINE and the Cluster of Excellence "CliSAP" projects funded by the German Research Foundation (SCHI 436/14-1, BO 1333/4-1, SCHO 739/14-1, EXC177). Finally, we would like to thank the anonymous referees for their constructive comments and suggestions, which helped to improve the manuscript. 
Edited by: Govindasamy Bala

Reviewed by: two anonymous referees

\section{References}

Alexandru, A., de Elia, R., Laprise, R., Separovic, L., and Biner, S.: Sensitivity Study of Regional Climate Model Simulations to Large-Scale Nudging Parameters, Mon. Weather Rev., 137, 1666-1686, https://doi.org/10.1175/2008MWR2620.1, 2008.

Argüeso, D., Hidalgo-Muñoz, J. M., Gámiz-Fortis, S. R., EstebanParra, M. J., Dudhia, J., and Castro-Díez, Y.: Evaluation of WRF Mean and Extreme Precipitation over Spain: Present Climate (1970-99), J. Climate, 25, 4883-4897, https://doi.org/10.1175/JCLI-D-11-00276.1, 2012.

Barros, A. P. and Lang, T. J.: Monitoring the Monsoon in the Himalayas: Observations in Central Nepal, June 2001, Mon. Weather Rev., 131, 1408-1427, 2003.

Bhate, A. J., Unnikrishnan, C. K., and Rajeevan, M.: Regional climate model simulations of the 2009 Indian summer monsoon, Indian J. Radio Sp. Phys., 41, 488-500, 2012.

Bhatt, B. C. and Nakamura, K.: A climatological-dynamical analysis associated with precipitation around the southern part of the Himalayas, J. Geophys. Res.-Atmos., 111, 1-13, https://doi.org/10.1029/2005JD006197, 2006.

Bhatt, B. C., Sobolowski, S., and King, M. P.: Assessment of downscaled current and future projections of diurnal rainfall patterns for the Himalaya, J. Geophys. Res.-Atmos., 119, 12512-533545, https://doi.org/10.1002/2014JD022134, 2014.

Böhner, J.: General climatic controls and topoclimatic variations in Central and High Asia, Boreas, 35, 279-295, https://doi.org/10.1111/j.1502-3885.2006.tb01158.x, 2006.

Böhner, J. and Lehmkuhl, F.: Environmental change modelling for Central and High Asia: Pleistocene, present and future scenarios, Boreas, 34, 220-231, https://doi.org/10.1111/j.15023885.2005.tb01017.x, 2005.

Böhner, J., Miehe, G., Miehe, S., and Nagy, L.: Climate and Weather variability: An introduction to the natural history, ecology, and human environment of the Himalayas, a companion volume to the flora of Nepal, Royal Botanic Garden Edinburgh, 4, 23-89, 2015.

Bookhagen, B. and Burbank, D. W.: Topography, relief, and TRMM-derived rainfall variations along the Himalaya, Geophys. Res. Lett., 33, 1-5, https://doi.org/10.1029/2006GL026037, 2006.

Bürzle, B., Schickhoff, U., Schickhoff, U., Schwab, N., Oldeland, J., Müller, M., Böhner, J., Chaudhary, R. P., Scholten, T. and Dickoré, W. B.: Phytosociology and ecology of treeline ecotone vegetation in Rolwaling Himal, Nepal, Phytocoenologia, https://doi.org/10.1127/phyto/2017/0130, 2017.

Cannon, F., Carvalho, L. M. V., Jones, C., and Bookhagen, B.: Multi-annual variations in winter westerly disturbance activity affecting the Himalaya, Clim. Dynam., 44, 441-455, https://doi.org/10.1007/s00382-014-2248-8, 2015.

Collier, E. and Immerzeel, W. W.: High-resolution modeling of atmospheric dynamics in the Nepalese H, J. Geophys. Res.-Atmos., 120, 9882-9896, https://doi.org/10.1002/2015JD023266, 2015.

Collins, W. D., Rasch, P. J., Boville, B. A., Hack, J. J., Williamson, D. L., Kiehl, J. T., Briegleb, B., Bitz, C. M., Lin, S.-J., Zhang, M., and Dai, Y.: Description of the NCAR Community Atmosphere Model (CAM 3.0), Ncar/Tn-464+Str, 1-214, 2004.

Dee, D. P., Uppala, S. M., Simmons, A. J., Berrisford, P., Poli, P., Kobayashi, S., Andrae, U., Balmaseda, M. A., Balsamo, G., Bauer, P., Bechtold, P., Beljaars, A. C. M., van de Berg, L., Bidlot, J., Bormann, N., Delsol, C., Dragani, R., Fuentes, M., Geer, A. J., Haimberger, L., Healy, S. B., Hersbach, H., Hólm, E. V., Isaksen, L., Kållberg, P., Köhler, M., Matricardi, M., McNally, A. P., Monge-Sanz, B. M., Morcrette, J.-J., Park, B.-K., Peubey, C., de Rosnay, P., Tavolato, C., Thépaut, J.-N., and Vitart, F.: The ERA-Interim reanalysis: configuration and performance of the data assimilation system, Q. J. Roy. Meteor. Soc., 137, 553-597, https://doi.org/10.1002/qj.828, 2011.

Gerlitz, L.: Using fuzzified regression trees for statistical downscaling and regionalization of near surface temperatures in complex terrain: A case study from Khumbu Himal, Theor. Appl. Climatol., 122, 337-352, https://doi.org/10.1007/s00704-014-1285-x, 2014.

Gerlitz, L., Conrad, O., and Böhner, J.: Large-scale atmospheric forcing and topographic modification of precipitation rates over High Asia - a neural-network-based approach, Earth Syst. Dynam., 6, 61-81, https://doi.org/10.5194/esd-6-61-2015, 2015.

Gerlitz, L., Bechtel, B., Böhner, J., Bobrowski, M., Bürzle, B., Müller, M., Scholten, T., Schickhoff, U., Schwab, N., and Weidinger, J.: Analytic Comparison of Temperature Lapse Rates and Precipitation Gradients in a Himalayan Treeline Environment: Implications for Statistical Downscaling, in: Climate Change, Glacier Response, and Vegetation Dynamics in the Himalaya: Contributions Toward Future Earth Initiatives, edited by: Singh, R. B., Schickhoff, U., and Mal, S., Springer International Publishing, Cham., 49-64, 2016.

Goodison, B. E., Louie, P. Y. T., and Yang, D.: WMO solid precipitation measurement intercomparison, WMO Instruments and Observing Methods Rep. 67, WMO/ TD-872, 212 pp., 1998.

Hasson, S., Pascale, S., Lucarini, V., and Böhner, J.: Seasonal cycle of precipitation over major river basins in South and Southeast Asia: A review of the CMIP5 climate models data for present climate and future climate projections, Atmos. Res., 180, 42-63, 2016a.

Hasson, S., Gerlitz, L., Scholten, T., Schickhoff, U., and Böhner, J.: Recent Climate Change over High Asia, in: Climate Change, Glacier Response, and Vegetation Dynamics in the Himalaya, 29-48, Springer International Publishing, 2016b.

Hasson, S.: Seasonality of Precipitation over Himalayan Watersheds in CORDEX South Asia and their Driving CMIP5 Experiments, Atmosphere, 7, 123, https://doi.org/10.3390/atmos7100123, 2016c.

Haslinger, K., Anders, I., and Hofstätter, M.: Regional climate modelling over complex terrain: an evaluation study of COSMOCLM hindcast model runs for the Greater Alpine Region, Clim. Dynam., 40, 511-529, https://doi.org/10.1007/s00382012-1452-7, 2013.

Higuchi, K., Ageta, Y., Yasunari, T., and Inoue, J.: Characteristics of precipitation during the monsoon season in high-mountain areas of the Nepal Himalaya, Hydrol. Asp. Alp. High Mt. Area, 138, 21-30, 1982.

Immerzeel, W. W., Petersen, L., Ragettli, S., and Pellicciotti, F.: The importance of observed gradients of air temperature and precipitation for modeling runoff from a glacierized watershed 
in the Nepalese Himalayas, Water Resour. Res., 50, 2212-2226, https://doi.org/10.1002/2013WR014506, 2014.

Jiménez, P. A. and Dudhia, J.: On the Ability of the WRF Model to Reproduce the Surface Wind Direction over Complex Terrain, J. Appl. Meteorol. Climatol., 52, 1610-1617, https://doi.org/10.1175/JAMC-D-12-0266.1, 2013.

Jiménez, P. A., Dudhia, J., González-Rouco, J. F., Navarro, J., Montávez, J. P., and García-Bustamante, E.: A Revised Scheme for the WRF Surface Layer Formulation, Mon. Weather Rev., 140, 898-918, https://doi.org/10.1175/MWR-D-11-00056.1, 2012.

Jones, R. G., Murphy, J. M., and Noguer, M.: Simulation of climate change over Europe using a nested regional climate model I: assessment of control climate, including sensitivity to location of lateral boundaries, Q. J. Roy. Meteor. Soc., 121, 1413-1449, https://doi.org/10.1002/qj.49712152610, 1995.

Kain, J. S.: The Kain-Fritsch convective parameterization: An update, J. Appl. Meteorol., $43, \quad 170-181, \quad$ https://doi.org/10.1175/15200450(2004)043<0170:TKCPAU>2.0.CO;2, 2004.

Karki, M., Mool, P., and Shrestha, A.: Climate Change and its Increasing Impacts in Nepal, The Initiation, 3, 30-37, https://doi.org/10.3126/init.v3i0.2425, 2009.

Karki, R.: Intercomparision of snowfall measured by weighing and tipping bucket precipitation gauges at Jumla Airport, Conference paper, available at: https://www.wmo.int/pages/prog/www/ IMOP/publications/IOM-109_TECO-2012/Session2/O2_02_ Karki_Intercomparison_of_Snowfall_Measurements_Nepal.pdf (last access: 12 March 2017), Nepal, 2012.

Karki, R., Talchabhadel, R., Aalto, J., and Baidya, S. K.: New climatic classification of Nepal, Theor. Appl. Climatol., 125, 799808, https://doi.org/10.1007/s00704-015-1549-0, 2016.

Karki, R., Hasson, S., Schickhoff, U., Scholten, T., and Böhner, J.: Rising Precipitation Extremes across Nepal, Climate, 5, 4, https://doi.org/10.3390/cli5010004, 2017.

Karmacharya, J., Jones, R., Moufouma-Okia, W., and New, M.: Evaluation of the added value of a high-resolution regional climate model simulation of the South Asian summer monsoon climatology, Int. J. Climatol., 37, 3630-3643, https://doi.org/10.1002/joc.4944, 2016.

Kattel, D. B., Yao, T., Yang, K., Tian, L., Yang, G., and Joswiak, D.: Temperature lapse rate in complex mountain terrain on the southern slope of the central Himalayas, Theor. Appl. Climatol., 113, 671-682, https://doi.org/10.1007/s00704-012-0816-6, 2013.

Lang, T. J. and Barros, A. P.: Winter Storms in the Central Himalayas, J. Meteorol. Soc. Jpn., 82, 829-844, https://doi.org/10.2151/jmsj.2004.829, 2004.

Maussion, F., Scherer, D., Mölg, T., Collier, E., Curio, J., and Finkelnburg, R.: Precipitation seasonality and variability over the Tibetan Plateau as resolved by the high Asia reanalysis, J. Climate, 27, 1910-1927, https://doi.org/10.1175/JCLI-D-13$00282.1,2014$.

Miehe, G.: Langtang Himal. A Prodormus of the Vegetation Ecology of the Himalayas. Mit Einer Kommentierten Flechtenliste von Josef Poelt, Borntrager, Stuttgart, Germany, 1990.

Morrison, H., Thompson, G., and Tatarskii, V.: Impact of Cloud Microphysics on the Development of Trailing Stratiform Precipitation in a Simulated Squall Line: Comparison of One- and Two-Moment Schemes, Mon. Weather Rev., 137, 991-1007, https://doi.org/10.1175/2008MWR2556.1, 2009.
Müller, M., Schickhoff, U., Böhner, J., Chaudhary, R. P., Drollinger, S., and Scholten, T.: How do soil properties affect alpine treelines? General principles in a global perspective and novel findings from Rolwaling Himal, Nepal, Prog. Phys. Geogr., 40, 135160, https://doi.org/10.1177/0309133315615802, 2016a.

Müller, M., Schwab, N., Schickhoff, U., Böhner, J., and Scholten, T.: Soil temperature and soil moisture patterns in a Himalayan alpine treeline ecotone, Arctic Alpine Res., 48, 501-521, https://doi.org/10.1657/AAAR0016-004, 2016b.

Mynsbrugge, J. V.: Bidding Strategies Using Price Based Unit Commitment in a Deregulated Power Market, K. U. Leuven, available at: http://en.wikipedia.org/wiki/Mean_absolute_ percentage_error (last access: 11 May 2017), 2010.

Nakanishi, M. and Niino, H.: An Improved Mellor-Yamada Level3 Model: Its Numerical Stability and Application to a Regional Prediction of Advection Fog, Boundary-Lay. Meteorol., 119, 397-407, https://doi.org/10.1007/s10546-005-9030-8, 2006.

Niu, G.-Y., Yang, Z.-L., Mitchell, K. E., Chen, F., Ek, M. B., Barlage, M., Kumar, A., Manning, K., Niyogi, D., Rosero, E., Tewari, M., and Xia, Y.: The community Noah land surface model with multiparameterization options (Noah-MP): 1. Model description and evaluation with localscale measurements, J. Geophys. Res.-Atmos., 116, D12109, https://doi.org/10.1029/2010JD015139, 2011.

Norris, J., Carvalho, L. M. V., Jones, C., and Cannon, F.: WRF simulations of two extreme snowfall events associated with contrasting extratropical cyclones over the western and central Himalaya, J. Geophys. Res.-Atmos., 120, 3114-3138, https://doi.org/10.1002/2014JD022592, 2015.

Norris, J., Carvalho, L. M. V., Jones, C., Cannon, F., Bookhagen, B., Palazzi, E., and Tahir, A. A.: The spatiotemporal variability of precipitation over the Himalaya: evaluation of one-year WRF model simulation, Clim. Dynam., 1-26, https://doi.org/10.1007/s00382-016-3414-y, 2016.

Otte, T. L., Nolte, C. G., Otte, M. J., and Bowden, J. H.: Does nudging squelch the extremes in regional climate modeling?, J. Climate, 25, 7046-7066, https://doi.org/10.1175/JCLI-D-1200048.1, 2012.

Palazzi, E., von Hardenberg, J., and Provenzale, A.: Precipitation in the Hindu-Kush Karakoram Himalaya: Observations and future scenarios, J. Geophys. Res.-Atmos., 118, 85-100, https://doi.org/10.1029/2012JD018697, 2013.

Pohl, B. and Crétat, J.: On the use of nudging techniques for regional climate modeling: application for tropical convection, Clim. Dynam., 43, 1693-1714, https://doi.org/10.1007/s00382013-1994-3, 2014.

Putkonen, J. K.: Continuous Snow and Rain Data at 500 to $4400 \mathrm{~m}$ Altitude near Annapurna, Nepal, 1999-2001, Arct. Antarct. Alp. Res., 36, 244-248, https://doi.org/10.1657/15230430(2004)036[0244:CSARDA]2.0.CO;2, 2004.

Raju, A., Parekh, A., Chowdary, J. S., and Gnanaseelan, C.: Assessment of the Indian summer monsoon in the WRF regional climate model, Clim. Dynam., 44, 3077-3100, https://doi.org/10.1007/s00382-014-2295-1, 2015.

Rasmussen, R., Liu, C., Ikeda, K., Gochis, D., Yates, D., Chen, F., Tewari, M., Barlage, M., Dudhia, J., Yu, W., and Miller, K.: High-Resolution Coupled Climate Runoff Simulations of Seasonal Snowfall over Colorado: A Process Study 
of Current and Warmer Climate, J. Climate, 24, 3015-3048, https://doi.org/10.1175/2010JCLI3985.1, 2011.

Sahany, S., Venugopal, V., and Nanjundiah, R. S.: Diurnal-scale signatures of monsoon rainfall over the Indian region from TRMM satellite observations, J. Geophys. Res.-Atmos., 115, D02103, https://doi.org/10.1029/2009JD012644, 2010.

Salerno, F., Guyennon, N., Thakuri, S., Viviano, G., Romano, E., Vuillermoz, E., Cristofanelli, P., Stocchi, P., Agrillo, G., Ma, Y., and Tartari, G.: Weak precipitation, warm winters and springs impact glaciers of south slopes of Mt. Everest (central Himalaya) in the last 2 decades (1994-2013), The Cryosphere, 9, 12291247, https://doi.org/10.5194/tc-9-1229-2015, 2015.

Sato, T., Yoshikane, T., Satoh, M., Miura, H., and Fujinami, H.: Resolution Dependency of the Diurnal Cycle of Convective Clouds over the Tibetan Plateau in a Mesoscale Model, J. Meteorol. Soc. Jpn., 86A, 17-31, https://doi.org/10.2151/jmsj.86A.17, 2008.

Schickhoff, U., Bobrowski, M., Böhner, J., Bürzle, B., Chaudhary, R. P., Gerlitz, L., Heyken, H., Lange, J., Müller, M., Scholten, T., Schwab, N., and Wedegärtner, R.: Do Himalayan treelines respond to recent climate change? An evaluation of sensitivity indicators, Earth Syst. Dynam., 6, 245-265, https://doi.org/10.5194/esd-6-245-2015, 2015.

Schwab, N., Schickhoff, U., Müller, M., Gerlitz, L., Bürzle, B., Böhner, J., Chaudhary, R. P., and Scholten, T.: Treeline Responsiveness to Climate Warming: Insights from a Krummholz Treeline in Rolwaling Himal, Nepal, in: Climate Change, Glacier Response, and Vegetation Dynamics in the Himalaya: Contributions Toward Future Earth Initiatives, edited by: Singh, R. B., Schickhoff, U., and Mal, S., 307-345, Springer International Publishing, Cham., 2016.

Seko, K.: Seasonal variation of altitudinal dependence of precipitation in Langtang Valley, Napal Himalayas, Bull. Glacier Res., 5, 41-47, 1987.

Shrestha, A.: Cloudbursts in the Nepal Himalayas: Interaction between the Indian monsoon and extratropics, $\mathrm{PhD}$ thesis, University of Wisconsin-Madison, USA, 2016.

Shrestha, D. and Deshar, R.: Spatial Variations in the Diurnal Pattern of Precipitation over Nepal Himalayas, Nepal, J. Sci. Technol., 15, 57-64, https://doi.org/10.1007/s00704-008-0045$1,2014$.

Shrestha, D., Singh, P., and Nakamura, K.: Spatiotemporal variation of rainfall over the central Himalayan region revealed by TRMM Precipitation Radar, J. Geophys. Res.-Atmos., 117, 114, https://doi.org/10.1029/2012JD018140, 2012.
Shrestha, M. L.: Interannual variation of summer monsoon rainfall over Nepal and its relation to Southern Oscillation Index, Meteorol. Atmos. Phys., 75, 21-28, https://doi.org/10.1007/s007030070012, 2000.

Shrestha, M., Wang, L., Koike, T., Xue, Y., and Hirabayashi, Y.: Modeling the Spatial Distribution of Snow Cover in the Dudhkoshi Region of the Nepal Himalayas, J. Hydrometeorol., 13, 204-222, https://doi.org/10.1175/JHM-D-10-05027.1, 2011.

Soares, P. M. M., Cardoso, R. M., Miranda, P. M. A., de Medeiros, J., Belo-Pereira, M., and Espirito-Santo, F.: WRF high resolution dynamical downscaling of ERA-Interim for Portugal, Clim. Dynam., 39, 2497-2522, https://doi.org/10.1007/s00382-012-1315$2,2012$.

Soncini, A., Bocchiola, D., Confortola, G., Minora, U., Vuillermoz, E., Salerno, F., Viviano, G., Shrestha, D., Senese, A., Smiraglia, C., and Diolaiuti, G.: Future hydrological regimes and glacier cover in the Everest region: The case study of the upper Dudh Koshi basin, Sci. Total Environ., 565, 1084-1101, https://doi.org/10.1016/j.scitotenv.2016.05.138, 2016.

Talchabhadel, R., Karki, R., and Parajuli, B.: Intercomparison of precipitation measured between automatic and manual precipitation gauge in Nepal, Measurement, 106, 264-273, https://doi.org/10.1016/j.measurement.2016.06.047, 2017.

Ueno, K., Toyotsu, K., Bertolani, L., and Tartari, G.: Stepwise Onset of Monsoon Weather Observed in the Nepal Himalaya, Mon. Weather Rev., 136, 2507-2522, https://doi.org/10.1175/2007MWR2298.1, 2008.

Viale, M., Houze, R. A., and Rasmussen, K. L.: Upstream Orographic Enhancement of a Narrow Cold-Frontal Rainband Approaching the Andes, Mon. Weather Rev., 141, 1708-1730, https://doi.org/10.1175/MWR-D-12-00138.1, 2013.

Von Storch, H., Langenberg, H., and Feser, F.: A spectral nudging technique for dynamical downscaling purposes, Mon. Weather Rev., 128, 3664-3673, 2000.

Wagnon, P., Vincent, C., Arnaud, Y., Berthier, E., Vuillermoz, E., Gruber, S., Ménégoz, M., Gilbert, A., Dumont, M., Shea, J. M., Stumm, D., and Pokhrel, B. K.: Seasonal and annual mass balances of Mera and Pokalde glaciers (Nepal Himalaya) since 2007, The Cryosphere, 7, 1769-1786, https://doi.org/10.5194/tc7-1769-2013, 2013.

Wang, S. Y., Fosu, B., Gillies, R. R., and Singh, P. M.: The deadly Himalayan snowstorm of October 2014: synoptic 15 conditions and associated trends, B. Am. Meteorol. Soc., 96, S89-S94, https://doi.org/10.1175/BAMS-D-15-00113.1, 2015. 